\title{
Quantification of Proteins Involved in Drug Metabolism and Disposition in the Human Liver Using Label-Free Global Proteomics
}

DOI:

10.1021/acs.molpharmaceut.8b00941

\section{Document Version}

Accepted author manuscript

Link to publication record in Manchester Research Explorer

Citation for published version (APA):

Couto, N., Al-Majdoub, Z., Achour, B., Wright, P., Rostami-Hodjegan, A., \& Barber, J. (2019). Quantification of Proteins Involved in Drug Metabolism and Disposition in the Human Liver Using Label-Free Global Proteomics. Molecular Pharmaceutics, 16(2), 632-647. https://doi.org/10.1021/acs.molpharmaceut.8b00941

\section{Published in:}

Molecular Pharmaceutics

\section{Citing this paper}

Please note that where the full-text provided on Manchester Research Explorer is the Author Accepted Manuscript or Proof version this may differ from the final Published version. If citing, it is advised that you check and use the publisher's definitive version.

\section{General rights}

Copyright and moral rights for the publications made accessible in the Research Explorer are retained by the authors and/or other copyright owners and it is a condition of accessing publications that users recognise and abide by the legal requirements associated with these rights.

\section{Takedown policy}

If you believe that this document breaches copyright please refer to the University of Manchester's Takedown Procedures [http://man.ac.uk/04Y6Bo] or contact uml.scholarlycommunications@manchester.ac.uk providing relevant details, so we can investigate your claim.

\section{OPEN ACCESS}


This document is confidential and is proprietary to the American Chemical Society and its authors. Do not copy or disclose without written permission. If you have received this item in error, notify the sender and delete all copies.

\section{Quantification of Proteins Involved in Drug Metabolism and Disposition in the Human Liver using Label-Free Global Proteomics}

\begin{tabular}{|r|l|}
\hline Journal: & Molecular Pharmaceutics \\
\hline Manuscript ID & mp-2018-00941w.R1 \\
\hline Manuscript Type: & Article \\
\hline Duthor: & n/a \\
\hline Complete List of Authors: & $\begin{array}{l}\text { Couto, Narciso; University of Sheffield, Department of Chemical and } \\
\text { Biological Engineering, ChELSI Institute (Chemical Engineering at the } \\
\text { Life Science Interface); University of Manchester, Centre for Applied } \\
\text { Pharmacokinetic Research } \\
\text { Al-Majdoub, Zubida; University of Manchester, Centre for Applied } \\
\text { Pharmacokinetic Research } \\
\text { Achour, Brahim; University of Manchester, Centre for Applied } \\
\text { Pharmacokinetic Research } \\
\text { Wright, Phillip; University of Sheffield, Department of Chemical and } \\
\text { Biological Engineering, ChELSI Institute (Chemical Engineering at the } \\
\text { Life Science Interface); Newcastle University, School of Engineering, } \\
\text { Faculty of Science, Agriculture \& Engineering } \\
\text { Rostami-Hodjegan, Amin; University of Manchester, Centre for Applied } \\
\text { Pharmacokinetic Research; Simcyp Ltd. (a Certara company) } \\
\text { Barber, Jill; University of Manchester, Centre for Applied Pharmacokinetic } \\
\text { Research }\end{array}$ \\
\hline
\end{tabular}

\section{SCHOLARONE ${ }^{\text {m }}$ Manuscripts}




\section{Quantification of Proteins Involved in Drug Metabolism and Disposition in the Human Liver using Label-Free Global Proteomics}

Narciso Couto§ł¥*, Zubida M. Al-Majdoub\$, Brahim Achour§, Phillip C. Wright"t, Amin RostamiHodjegan§‡, Jill Barber§*

\$Centre for Applied Pharmacokinetic Research, University of Manchester, Stopford Building, Oxford Road, Manchester, M13 9PT, UK.

tDepartment of Chemical and Biological Engineering, ChELSI Institute (Chemical Engineering at the Life Science Interface), University of Sheffield, Sir Robert Hadfield Building, Mappin Street, Sheffield S1 3JD, UK.

"Now at: School of Engineering, Faculty of Science, Agriculture \& Engineering, Newcastle University, Newcastle upon Tyne, NE1 7RU, UK.

¥Simcyp Ltd. (a Certara company), 1 Concourse Way, Sheffield, S1 2BJ, UK.

* These authors contributed equally to this work.

*To whom correspondence should be addressed: narciso.couto@manchester.ac.uk; jill.barber@manchester.ac.uk

KEYWORDS: Human liver microsomes (HLM), cytochrome P450 (CYP), uridine 5'-diphosphateglucuronosyltransferase (UGT), ATP-binding cassette (ABC) drug transporters, solute carrier (SLC) drug transporters, label-free proteomics. 


\section{ABSTRACT}

There is an urgent need (recognised in FDA guidance, 2018) to optimise the dose of medicines given to patients for maximal drug efficacy and limited toxicity (precision dosing), which can be facilitated by quantitative systems pharmacology (QSP) models. Accurate quantification of proteins involved in drug clearance is essential to build and improve QSP models for any target population. Here we describe application of label-free proteomics, in microsomes from 23 human livers, to simultaneously quantify 188 enzymes and 66 transporters involved in xenobiotic disposition, including 17 CYPs, 10 UGTs, 7 ABC and 11 SLC transporters; six of these proteins are quantified for the first time. The methodology allowed quantification of thousands of proteins, allowing estimation of sample purity and understanding of global patterns of protein expression. There was overall good agreement with targeted quantification and enzyme activity data, where this was available. The effects of sex, age, genotype and BMI on enzyme and transporter expression were assessed. Decreased expression of enzymes and transporters with increasing BMI was observed, but a tendency for older donors to have higher BMls may have confounded this result. The effect of genotype on enzymes expression was, however, clear-cut, with CYP3A5*1/*3 genotype expressed 16 -fold higher compared with its mostly inactive ${ }^{*} 3 /{ }^{*} 3$ counterpart. Despite the complex, time-consuming data analysis required for label-free methodology, the advantages of label-free method make it a valuable approach to populate a broad range of system parameters simultaneously for target patients within pharmacology and toxicology models.

\section{INTRODUCTION}

Quantitative systems pharmacology (QSP) models, such as physiologically-based pharmacokinetic (PBPK) models are increasingly used to predict appropriate doses of drugs for patient groups, especially groups that may not be assessed during clinical trials (young, old, pregnant and chronically diseased patients, for example). Over 30 recent drug labels have benefitted from model-informed decisions about 
dosing in lieu of clinical studies ${ }^{1,2}$ Publication of the final FDA guidance in using PBPK models is another indication of the fact that these models are here to stay. ${ }^{3}$

In the human liver, cytochrome P450 (CYP) and uridine 5'-diphosphate-glucuronosyltransferase (UGT) enzymes, in combination with uptake and efflux transporters, play a vital role in the disposition of most drugs and xenobiotics. Because of factors such as genetic predisposition, lifestyle choices, age and disease, the expression of these proteins varies considerably among individuals. ${ }^{4}$ As a result, drug treatments can vary in efficacy from patient to patient and toxic side effects may develop in certain populations. ${ }^{4}$ The reliable prediction of drug behaviour and safety across all populations is of paramount importance to the design and development of novel drugs and is of considerable value to pharmaceutical industries and regulatory authorities. ${ }^{1,5}$

The abundance of specific proteins in the human liver has been measured in either tissue lysates or enriched microsomal fractions, using targeted mass spectrometry-based quantitative proteomics approaches which require the use of stable isotope-labelled standards, either in the form of concatenated proteotypic peptides (QconCAT) or as synthetic peptides (AQUA). ${ }^{6-11}$ The crucial requirement of such targeted proteomic approaches is a set of unique peptides per protein under study with proven flyability in the mass spectrometer. ${ }^{12}$ The use of targeted proteomics approaches for the quantification of CYPs, UGTs and transporters has resulted in disparities in reported protein abundances. ${ }^{13}$ This can be attributed to inter-laboratory variability in the choice of standard peptides. In addition, differences in sample preparation methods and the technical difficulties presented by these proteins, particularly the high level of sequence similarity between the proteins within their respective sub-families, have obscured genuine inter-individual differences in protein expression. ${ }^{13}$ The lack of a standardised, systematic methodology for all steps in the quantification of protein abundance, from tissue collection to mass spectrometric analysis, has recently been recognised as a major obstacle to generating consistent 


4

proteomic data. ${ }^{14,15} \mathrm{~A}$ further inherent limitation of targeted proteomics is that the number of proteins that can be simultaneously analysed is limited. Therefore, a comprehensive investigation of all relevant drug metabolising enzymes and transporters using targeted proteomics is time-consuming and costly. The resource implications of targeted vs untargeted analysis have been previously analysed and shown that the targeted methodology is not economically justified when a comprehensive analysis of drug metabolising enzymes and transporters is desired. ${ }^{16}$ Label-free proteomic quantification of drug metabolising enzymes and transporters is therefore an attractive alternative. Label-free methods do not require the prior manual selection of unique peptides for protein quantification; instead, protein quantification is based on the intensities of peaks corresponding to all unique peptides detected by the mass spectrometer. ${ }^{17,18}$ The advantage of label-free methods is that they enable the simultaneous quantification of large numbers of proteins allowing a systems-level understanding of the protein complement within an individual and across populations. ${ }^{19}$ However, measurement of low abundance proteins using global proteomic methods still require further optimization and reported correlations between targeted and global analyses are less well-established. ${ }^{15,19}$

We aimed in this study to quantify a wide range of proteins relevant to the fate of drugs in humans. To our knowledge, the current report represents the most comprehensive analysis of the abundance of drug metabolising enzymes, particularly CYPs and UGTs, and drug transporters in human liver microsomal fractions to date using a label-free quantitative proteomic approach. This systematic study allows the evaluation of the global proteomic profile of the samples as well. This allowed an assessment of the purity of the microsomal samples. In addition, we were able to investigate the implication of the dynamic range of the proteome on the comparative analysis of protein abundance between individuals, and the excellent correlations between protein abundance against in vitro enzymatic activity and demographic characteristics. 


\section{MATERIALS AND METHODS}

\section{Chemicals \\ Unless otherwise indicated, all chemicals were supplied by Sigma-Aldrich (Poole, Dorset, UK) with the highest purity available. Sequencing grade modified trypsin was supplied by Promega (Southampton, UK). All solvents were HPLC grade and supplied by ThermoFisher Scientific (Paisley, UK). \\ Human liver microsomal samples}

Human liver microsomes (HLM) from non-tumorous liver samples $(n=23)$ were provided by Pfizer (Groton, CT, USA). Suppliers of these samples were Vitron (Tucson, AZ, USA) and BD Gentest (San Jose, CA, USA). Demographic (ethnicity, age and gender), clinical (medical history, medications, smoking history and alcohol consumption) and genotype information of these donors were also provided by Pfizer (Supplementary Table 1). The 23 donors (10 females, 13 males) had an average age of 48.7 years (range: 27-66 years) and an average BMl of $29.7 \mathrm{~kg} \mathrm{~m}^{-2}$ (range: $18.0-39.6 \mathrm{~kg} \mathrm{~m}^{-2}$ ), including 9 over-weight and 9 obese donors. Ethical approval was obtained by the suppliers and the sample donors were anonymised. These samples have previously been analysed by targeted quantitative proteomics..$^{10,11,20}$ In the present study, label-free quantification was applied to these samples according the workflow shown in Supplementary Figure 1. Liver microsomal fractions were prepared using differential centrifugation methodology as previously descrived. ${ }^{21}$ Briefly, low speed centrifugation $(10,000 \mathrm{~g})$ was performed to separate cellular debris from the crude cytosolic fraction made up of cytosolic components and low weight organelles. High speed centrifugation $(100,000 \mathrm{~g})$ was performed to pellet the microsomal fraction.

\section{Protein content quantification and sample preparation}


Protein content in the HLM samples was estimated by a spectrophotometric protein assay using the Bradford reagent (ThermoFisher Scientific, Hemel Hempstead, UK). ${ }^{22}$ Analysis was made in triplicate according to the manufacturer's protocol using bovine serum albumin (BSA) as a standard. Microsomal fractions from 23 individuals were selected in this study. To enable absolute quantification by mass spectrometry, $100 \mu \mathrm{g}$ of each HLM fraction was spiked with an internal standard protein mixture containing $0.3 \mu \mathrm{g}$ of equine myoglobin, $0.15 \mu \mathrm{g}$ of bovine cytochrome $c$ and $0.2 \mu \mathrm{g}$ of BSA. These nonhuman proteins were selected because their low similarity with their human counterparts minimises interference. To each fraction containing the standards,sodium deoxycholate was added to achieve a final concentration of $10 \%(\mathrm{w} / \mathrm{v})$. The mixture was mixed well and incubated at room temperature for 10 minutes.

For protein digestion, a the filter-aided sample preparation (FASP) method was used as previously described with minor modifications, in order to optimise for microsomal samples. ${ }^{14,23}$ Before sample addition, Amicon Ultra $0.5 \mathrm{~mL}$ centrifugal filters at $3 \mathrm{kDa}$ molecular weight cut-off Merck Millipore, Nottingham, UK) were conditioned by briefly centrifuging $400 \mu \mathrm{L}$ of $60 \%(\mathrm{v} / \mathrm{v})$ methanol at $14,000 \mathrm{~g}$ at room temperature. The deoxycholate-solubilized HLM samples were then transferred to the conditioned filter units. A final concentration of $100 \mathrm{mM}$ 1,4-dithiothreitol (DTT) was added to the protein mixture, which was incubated at $56^{\circ} \mathrm{C}$ for 40 minutes. Following incubation, the samples were centrifuged at $14,000 \mathrm{~g}$ at room temperature for $20 \mathrm{~min}$. Alkylation was performed with $50 \mathrm{mM}$ iodoacetamide in the dark for 30 minutes at room temperature.

After alkylation, deoxycholate removal was performed by buffer exchange using two successive washes with $8 \mathrm{M}$ urea in $100 \mathrm{mM}$ Tris- $\mathrm{HCl}(\mathrm{pH}$ 8.5). To reduce urea concentration, three additional washes were performed using $1 \mathrm{M}$ urea in $50 \mathrm{mM}$ ammonium bicarbonate ( $\mathrm{pH}$ 8.5). Protein digestion was achieved by adding trypsin (trypsin:protein ratio $1: 25$ ) followed by overnight incubation at $37^{\circ} \mathrm{C}$. Peptides were 
recovered by centrifugation (14,000 $\mathrm{g}, 20 \mathrm{~min}$ ) first by elution using $100 \mathrm{mM}$ ammonium bicarbonate $(\mathrm{pH}$ 8.5) followed by a second elution using $0.5 \mathrm{M}$ sodium chloride. The eluted peptides were dried in a vacuum concentrator. The dried peptides were resuspended in loading buffer $(3 \%(\mathrm{v} / \mathrm{v})$ acetonitrile in water with $0.1 \%(\mathrm{v} / \mathrm{v})$ trifluroacetic acid) and desalted using a C18 column (Nest group, USA). The peptides were again dried using a vacuum concentrator and stored at $-20^{\circ} \mathrm{C}$ until mass spectrometric analysis.

\section{Liquid chromatography and tandem mass spectrometry (LC-MS/MS)}

Dried peptides samples were resuspended in $100 \mu \mathrm{L}$ of loading buffer and $1.0 \mu \mathrm{L}$ of each sample was loaded on an UltiMate ${ }^{\circledR} 3000$ rapid separation liquid chromatography (RSLC) (Dionex, Surrey, UK) coupled to an on-line Q Exactive ${ }^{\mathrm{TM}} \mathrm{HF}$ Hybrid Quadrupole-Orbitrap ${ }^{\mathrm{TM}}$ Mass Spectrometer (ThermoFisher Scientific, Bremen, Germany). The samples were analyzed in analytical duplicates (46 runs in total). Peptides were reversed-phase separated on a PepMap ${ }^{\text {TM }}$ RSLC C18 column ( $2 \mu \mathrm{m}$ particles, $100 \AA, 75$ $\mu \mathrm{m}$ inner diameter, $50 \mathrm{~cm}$ length) (Thermo Scientific, UK) preceded by a C18 PepMap100 $\mu$-precolumn ( $5 \mu \mathrm{m}, 100 \AA, 300 \mu \mathrm{m}$ inner diameter, $5 \mathrm{~mm}$ length) (ThermoFisher Scientific, UK). A multi-step gradient was used from $4 \%$ to $40 \%$ buffer B $(80 \%(\mathrm{v} / \mathrm{v})$ acetonitrile with $0.1 \%(\mathrm{v} / \mathrm{v})$ formic acid) for 100 minutes at

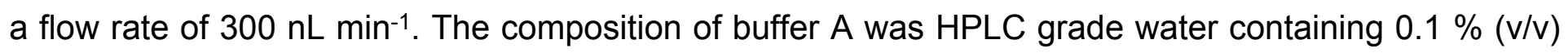
formic acid. The sensitivity and $\mathrm{m} / \mathrm{z}$ accuracy of the mass spectrometer was evaluated using a positive ion calibration solution (ThermoFisher Scientific, Paisley, UK). The performance of the liquid chromatographer and mass spectrometer was evaluated using HeLa protein digest standard (ThermoFisher Scientific, Paisley, UK) over a 90 min gradient. Data were acquired in the positive ion mode in a data-dependent manner alternating between survey MS and MS/MS scans. MS scans were performed over the range of $100-1500 \mathrm{~m} / \mathrm{z}$, with 60,000 resolution, automatic gain control (AGC) of $3 \times 10^{6}$, and $100 \mathrm{~ms}$ maximal injection time. The top 18 precursor ions were sequentially selected for 
fragmentation using higher-energy collisional dissociation (HCD) with $28 \%$ normalized collision energy and precursor isolation window of $1.2 \mathrm{~m} / \mathrm{z}$. MS/MS scans were acquired at 30,000 resolution, AGC of $5 \times 10^{4}$ and 120 ms maximal injection time. Dynamic exclusion was set to $30 \mathrm{~s}$.

\section{LC-MS/MS data analysis}

Protein/peptide identification and quantification was performed using Progenesis v4.0 (Nonlinear Dynamics, Newcastle-upon Tyne, UK) and Mascot (Matrix Science, London, UK). The Progenesis software was used for precursor ion alignment based on retention time. Following precursor alignment, data were exported as Mascot generic files (mgf) and subsequently proteins were identified using Mascot. Proteins were identified by searching against a reference human proteome database containing 71,599 entries (UniProt, May 2017). Using Mascot, the precursor mass tolerance was set to $5 \mathrm{ppm}$, fragment mass tolerance was set to $0.5 \mathrm{Da}$, cysteine carbamidomethylation was considered as fixed modification and oxidation of methionine and deamidation of asparagine/glutamine were considered as variable modifications. Trypsin was set as the proteolytic enzyme and one missed cleavage was allowed. The list of identified proteins was imported back into Progenesis and the identified proteins were matched with their abundance quantified using BSA as the internal standard of choice. Amongst the three proteins used as internal standards, BSA was selected because the amount of BSA spiked in to each sample was empirically in the right dynamic range of the proteins of interest. The abundance of each relevant protein was quantified by the 'Hi-N' method. ${ }^{24}$ In this method, the peak intensity associated with the $\mathrm{N}$ most abundant non-conflicting peptide ions were automatically selected for quantification. The mean value of the intensities of the three most intense unique peptides of the protein of interest relative to the internal standard was used for the calculation of the proportionality factor. ${ }^{24}$ The abundance of the protein of interest was calculated by multiplying the proportionality factor of each protein by the known abundance of BSA. Progenesis, in common with other mass spectrometry software, often identifies as 
"unique" peptides that are actually present in more than one cytochrome P450 or UGT enzyme. To overcome this limitation, the uniqueness of peptides from CYPs and UGTs was analysed using $p B L A S T$ search (NCBI, USA). The abundance of each CYP and UGT protein detected in the HLM samples was recalculated manually using the unique peptides identified using $p B L A S T$. The abundance was expressed in units of pmol $\mathrm{mg}^{-1}$ microsomal protein.

\section{Protein sub-cellular localization and annotation of enzymes and transporters}

To assess the purity and make-up of the microsomal fractions, the sub-cellular localization of all identified proteins $(n=2208)$ was annotated according to three databases: Gene Ontology (GO), UniProt and the Human Protein Atlas (HPA), by searching the gene names against these repositories. Where there was evidence of expression in more than one subcellular component, the protein was assigned to all relevant localizations. The identified enzymes and transporters were checked for evidence of expression in hepatic tissue at both the RNA and protein levels against the NCBI human database and HPA; only hepatic proteins were included in subsequent analysis. In addition, the role of hepatic enzymes and transporters was identified using UniProt and NCBI databases, leading to selection of proteins involved in xenobiotic/drug metabolism and disposition. Only drug metabolising enzymes and drug transporters quantifiable in at least one-third of the samples $(n \geq 7)$ were considered for subsequent statistical analysis.

\section{Cross-methodology assessment of measured enzyme abundance levels}

To establish the accuracy of the developed label-free assay, the abundance levels of enzymes measured in this study were compared to previously determined concentrations in matched samples using two targeted proteomic methodologies; QconCAT in the case of CYPs ${ }^{11}$ and UGTs, ${ }^{25}$ and AQUA in the case of UGTs. ${ }^{10}$

Assessment of CYP and UGT abundance against enzymatic activity 
To validate the proteomic method, assessment of direct correlation between the quantified abundance of major drug metabolizing CYPs and UGTs and their enzymatic activity was performed. Metabolite appearance rates for CYPs $(1 \mathrm{~A} 2,2 \mathrm{~B} 6,2 \mathrm{C} 9,2 \mathrm{C} 19,2 \mathrm{D} 6,3 \mathrm{~A} 4$ and $3 \mathrm{~A} 5)$ and for UGTs (1A1, 1A3, 1A4, $1 \mathrm{~A} 6,1 \mathrm{~A} 9,2 \mathrm{~B} 4,2 \mathrm{~B} 7$ and 2B15) in these samples were kindly provided by Pfizer (Groton, CT, USA). Cytochrome P450 substrates ${ }^{26}$ were: phenacetin (CYP1A2), bupropion (CYP2B6), diclofenac (CYP2C9), S-mephenytoin (CYP2C19), bufuralol (CYP2D6) and testosterone (CYP3A4). CYP3A5 activity was measured using midazolam in the presence of a CYP3cide to silence CYP3A4. ${ }^{27}$ UGT substrates 20,28 were: $\beta$-estradiol (UGT1A1), chenodeoxycholic acid (UGT1A3), trifluoperazine (UGT1A4), 5hydroxytryptophol (UGT1A6), propofol (UGT1A9), zidovudine (UGT2B7) andS-oxazepam (UGT2B15).

\section{Statistical analysis}

All statistical analysis of the data was performed using Microsoft Excel 2010,GraphPad Prism® v7.03 (La Jolla California, USA) and R v3.4.3. Non-parametric statistics were used since a considerable proportion of the dataset did not follow normal distribution. The normality of data distribution was assessed using three tests: D’Agostino-Pearson, Shapiro-Wilk and Kolmogorov-Sminovnormality tests. The Spearman rank-order correlation (Rs) test, with $t$-distribution of the $p$-values, was used to assess enzyme abundance-activity correlation and inter-correlation between protein abundance levels. The level of scatter of data was evaluated by linear regression $\left(R^{2}\right)$. The relationship between age and expression level was also assessed using these correlation tests. Differences between abundances generated by targeted (QconCAT/AQUA) and label-free methods were assessed using Mann-Whitney U-test and Kolmogorov-Sminov cumulative distribution test. Bias and scatter of the label free, AQUA and QconCAT datasets were assessed using average fold error (AFE) and absolute average fold error (AAFE), respectively. Differences between genotypes and BMI categories were assessed using non-parametric Kruskal-Wallis ANOVA followed by post-hoc Mann-Whitney U-test. $p$-value cut-off for statistical 
significance was set at 0.05 , which was Bonferroni-corrected when iterative tests were required to generate correlation matrices. Hierarchical cluster analysis (HCA) and principal components analysis (PCA) were performed using proteome-wide similarity data based on percentage identical peptide (PIP) and percentage identical protein (PIPr) ${ }^{23}$ values across the 23 samples. Graphs were generated using GraphPad Prism v7.03 and R v3.4.3.

\section{RESULTS}

\section{General outcome}

Across the twenty-three liver microsomal fractions, a total of 2208 proteins were quantified with a minimum of two unique peptides each and a false discovery rate of $\leq 1 \%$ at the protein and peptide levels. In each sample, an average of 1994 proteins was quantified (range 1836 - 2152 proteins). The present study represents an increase of approximately $30 \%$ of ADME proteins quantified in liver microsomal samples when comparing with previouly reported data. ${ }^{15,29}$

\section{Evaluation of the reproducibility of the proteomics data}

Analytical replicates were evaluated in two ways. Firstly, high reproducibility was seen in the quantified abundance of identical proteins across analytical replicates as the coefficient of determination from regression analysis $\left(R^{2}\right)$ varied between 0.79 and 0.99 , with a slope of approximately one. In addition,categorical evidence was used to assess the similarity between peptides identified in the analytical replicates at the level of the primary analytes (peptides) using the descriptor percentage identical peptides (PIP) as previously described. ${ }^{23}$ In each sample, a very high similarity was seen in the peptides identified in the analytical replicates with PIP varying between $92 \%$ and $100 \%$. The details of replicate evaluation are provided in Supplementary Table 2. Values in this range point to a high degree 
of consistency in both sample preparation and instrument performance and are reassuring, especially in view of the long mass spectrometry run required by 23 samples in duplicate.

\section{Assessment of the quality of liver microsomal fractions}

Sub-cellular localisation analysis of the samples predicted that approximately $50 \%$ of the quantified proteins were localised in the endoplasmic reticulum and the plasma membrane. The remaining proteins were largely predicted to be localised in the cytoplasm/cytosol, the mitochondria and the nucleus (Figure 1A). This prediction was confirmed by the presence of markers specific for these organelles. Although calnexin (CANX), the specific marker for endoplasmic reticulum membrane, was abundant in the global microsomal protein profile, markers for mitochondrial membrane (cytochrome c oxidase; COX4), plasma membrane (sodium/potassium-transporting ATPase subunit alpha-1 and cluster of differentiation 81; ATP1A1 and CD81) and peroxisomal membrane (peroxisomal membrane protein; PEX14) were also present (Figure 1B). ${ }^{30-32}$ Established protein markers for hepatocytes, asialoglycoprotein receptor 1 (ASGR1) and asialoglycoprotein receptor 2 (ASGR2), were highly expressed in the microsomal preparation, ${ }^{33,34}$ but markers specific to non-parenchymal endothelial cells (stabilin 1 and 2; STAB1/2) were also present, indicating some heterogeneity of cell type. ${ }^{35}$ Markers associated with other cell types such as Kupffer cells, Ito cells and intrahepatic cholangiocytes were not found. The heterogeneity of the microsomal samples makes this analysis especially important, as variation in contamination would have a profound effect on the apparent abundance of proteins involved in drug metabolism and transport when expressed as pmol of protein per microgram of microsomal protein, as is conventional. ${ }^{29,36,37}$

An analysis of the twenty most abundant proteins across all microsomal fractions was undertaken to determine whether the contaminants could affect the quantification of proteins in the microsomal fractions. In this study, fifteen out of the twenty most abundant proteins quantified in the microsomal 
fractions were predicted to be localised in the endoplasmic reticulum (Figure 1B). The most abundant protein in all microsomal fractions was either liver carboxylesterase 1 (CES1) or epoxide hydrolase 1 (EPHX1), both reticular proteins, at average concentrations of 360 and $247 \mathrm{pmol} \mathrm{mg}^{-1}$ liver microsomal protein, respectively. The twenty most abundant proteins constituted $22 \%-32 \%$ (average $24 \%$ ) of the quantified microsomal fraction (Figure 1C).

Assessment of the abundance of cytochrome P450 and uridine 5'-diphosphate-glucuronosyltransferase UGT enzymes and drug transporters

Cytochrome P450 (CYP) and uridine 5'-diphosphate-glucuronosyltransferase (UGT) enzymes are the principal enzymes responsible for the metabolism of drugs and xenobiotics. 188 of these enzymes and 66 transporters were quantified in at least seven individuals as shown in Supplementary Tables 8-11. These include 26 CYPs, 11 UGTs, 12 ATP-binding cassette (ABC) transporters and 52 solute carrier (SLC) transporters (Figures 1D and 1E). Of the quantified CYPs, UGTs and transporters, 17 CYPs, 10 UGTs, 7 ABC transporters and 11 SLC transporters are known to be associated with drug clearance based on pharmacological and toxicological evidence. Hepatic microsomal abundance levels of these enzymes and transporters are shown in Figure 2 and summarised in Tables 1-3. Where literature values were available, they were compared with the present study, and found to be in broad agreement (Supplementary Tables 4-7). The most highly expressed CYPs were CYP2E1, CYP2C9, CYP2C8,CYP3A4 and CYP2A6 (Figure 2A), ${ }^{6,38-40}$ The most highly expressed UGT was UGT2B7, followed by UGT1A4, UGT2B4,UGT1A1 and UGT2B15 (Figure 2B). The pie charts in Figure 2C and 2D show the relative abundance distribution of CYPs and UGTs involved in drug metabolism in the liver which are very similar to distributions reported in recent data analysis..$^{41,42}$ 
The most abundant $A B C$ transporter is $\mathrm{ABCC6}$ (Figure 2E) and SLCO1B1 is the most abundant transporter in the human liver (Figure $2 \mathrm{~F}$ ). ${ }^{6}$ Although we successfully quantified $A B C B 5, A B C G 8$ and SLC47A1, the expression level of these enzymes are not reported in Figures $2 \mathrm{E}$ and $2 \mathrm{~F}$ and Table 3 as these proteins were quantified in fewer than seven individuals. Enzymes and transporters involved in the metabolism and clearance of endogenous compounds were also quantified, including 9 CYPs, 1 UGT, 5 $A B C$ transporters and 41 SLC transporters (Figure $2 G$ ). Individual data for all enzymes and transporters quantified in this study are provided in Supplementary Tables 8-11. The abundance of enzymes and transporters was meadured in units of pmol $\mathrm{mg}^{-1}$ microsomal protein.

Comparison of CYP and UGT abundance in label-free and targeted proteomics measurements The HLM fractions here analysed by the label-free approach have previously been used to quantify the abundance of CYP and UGT enzymes using targeted proteomic approaches, ${ }^{10,11}$ presenting a unique opportunity for comparison of these proteomic workflows. The CYP enzymes have previously been quantified using a QconCAT-based strategy ${ }^{9}$, in which labelled standard peptides are concatenated together in an artificial protein and released by tryptic digestion. The UGTs have also been quantified by targeted approach, but using individual isotopic-labelled (AQUA) peptides as standards. ${ }^{8}$

Comparison of the median and distribution of CYP abundances quantified previously by the targeted QconCAT strategy ${ }^{11}$ with the label-free approach used in this study indicated that there was very good agreement between the studies across most of the quantified CYP enzymes, with less good, but still reasonable agreement for CYP2A6, CYP2B6 and CYP3A4 (Figure 3A and Suppmementary Figure 2). Analysis of fold-errors for individual microsomal samples assessed using the developed method relative to the targeted approach revealed that approximately $70 \%$ of the values generated by the two methods within 3 -fold, ${ }^{20}$ and $21 \%$ of values were within the bioequivalence range $(80 \%-125 \%) \cdot{ }^{43}$ Both bias 
(indicated by a value of the average fold error, AFE, different from 1) and scatter (indicated by an absolute average fold error, AAFE, higher than 1) were observed (Figure 3B).

UGT enzymes had previously been quantified by two targeted approaches, based on AQUA and QconCAT standards (Figure 3C Suppmementary Figure 2). The quantification of UGTs is extremely challenging because of (a) the very low abundance of some of these proteins, (b) the fact that they are membrane-bound and (c) the shared peptide sequences between UGTs, and hence, the difficulty in identifying unique peptides. Overall the present experiments reported lower abundances for the UGTs than either of the targeted methods, although again the values determined here fell within the range of UGT abundance reported in the literature (Supplementary Table 5) and a large proportion (approximately $64 \%$ ) of values were within 3 -fold, with a smaller proportion (17\%) within the bioequivalence range. ${ }^{20,43}$ Figure 3D shows the presence of both bias and scatter, when the methods were compared.

Correlation between CYPs and UGTs protein expression and enzymatic activity

The correlation between protein abundance quantified by the label-free approach and in vitro enzymatic activity was assessed for all CYP and UGT enzymes for which activity data were available. Correlations were deemed strong when the values correlated well (Rs> 0.60 with statistical significance against a Benferroni-corrected cut-off $p$-value) and demonstrated limited scatter $\left(R^{2}>0.30\right)$. The results demonstrated strong, significant and positive correlation between abundance and enzymatic activity across all CYP enzymes (Figure 4A). These correlations are better than those observed in a previous study using a targeted QconCAT strategy, ${ }^{9}$ thus highlighting the importance of the selection of peptide for quantification (Supplementary Tables 13-15). Strong positive correlation between protein abundance and enzymatic activity was also seen for two UGT enzymes, UGT1A3 and UGT1A4, with moderate positive correlation for the remaining UGT enzymes (Figure 4B). These correlations are comparable with 
those observed using a targeted AQUA strategy, ${ }^{20}$ which assessed correlation in a larger sample size ( $n$ = 59) compared to the current study $(n=23)$.

Covariates of expression of liver enzymes and transporters

Trends in the expression of enzymes and transporters were assessed with reference to several factors, including sex, age, genotype, smoking, alcohol consumption and body mass index (BMI) of donors. Demographic and clinical information of donors is provided in Supplementary Table 1. There were no significant differences in expression of enzymes between male and female donors (Figure 5A, 5B); the seemingly higher levels of CYP3A4 and 3A7 in female donors did not reach statistical significance (MannWhitney $U$-test, $P>0.05)$. A declining trend of expression with age was observed for enzymes and transporters, which did not reach statistical significance due to extensive scatter of the data, except for a few examples, including UGT2B15 (Figure 5C). Smoking and drinking did not seem to affect expression of enzymes; however, the number of smokers $(n=4)$ and regular alcohol consumers $(n=3)$ among the donors was very low for statistical assessment. The effect of genotype on expression was demonstrated by CYP3A5, with 16 -fold higher levels (Mann-Whitney U-test, $P<0.001$ ) observed with *1/*3 genotype compared to its mostly inactive ${ }^{*} 3{ }^{*} 3$ counterpart (Figure 5D). The effect of BMI was assessed in three categories (healthy weight: BMI 18.5-25kg m $\mathrm{k}^{-2}$, overweight: $25-30 \mathrm{~kg} \mathrm{~m}^{-2}$, and obese: $>30 \mathrm{~kg} \mathrm{~m}^{-2}$ ), and expression of enzymes and transporters tended to decline with increasing BMI (Figure 5E). Nonparametric (Kruskal-Wallis) ANOVA showed differences with borderline statistical significance for CYP2E1 $(P=0.08)$, and statistically significant differences for UGTs $1 A 3,1 A 4$, and 2B10, and transporters SLC27A2 and SLC27A5 $(P<0.05)$. Post-hoc Mann-Whitney U-test showed statistically significant differences between BMI categories for CYP2E1, UGTs 1A3, 1A4 and 2B10, and SLCs $27 \mathrm{~A} 2$ 
and $27 A 5(P<0.05)$. The average age for the three categories was $42.3,46.1$ and 55.4 years, so the effect of BMI may have been confounded by age.

\section{Correlations of expression between hepatic drug-metabolising enzymes and transporters}

Patterns in the expression of enzymes and transporters were also assessed for potential inter-correlation at the protein level. The heat map in Figure 6 shows normal log-transformed abundance levels of cytochrome P450 enzymes (Figure 6A) and UGT enzymes (Figure 6B). The clustering method was based on rank-order correlation. Examples of correlations in the CYP and UGT datasets are shown in Figure $6 \mathrm{C}$ and 6D, respectively. Observed inter-correlations between CYP enzymes included: CYP2C8/CYP2B6 (Rs $\left.=0.69, P=0.0003 ; R^{2}=0.30\right) ; C Y P 3 A 4 / C Y P 3 A 5 * 1{ }^{*} 3\left(R s=0.90, P=0.0004 ; R^{2}\right.$ $=0.74)$ and CYP2A6/CYP3A4 $\left(\mathrm{Rs}=0.67, \mathrm{P}=0.0009 ; \mathrm{R}^{2}=0.29\right)$. UGT correlations included: UGT1A4/UGT1A9 $\left(R s=0.63, P=0.001 ; R^{2}=0.23\right)$ and UGT1A4/UGT2B4 $\left(R s=0.63, P=0.001 ; R^{2}=\right.$ 0.29). Cross-family correlations were overall weak-to-moderate and included CYP3A4/UGT1A1 (Rs = $0.53, P=0.01 ; R^{2}=0.40$ ), which was previously reported to be moderate in a targeted experiment. ${ }^{11}$ These correlations are related to common regulatory mechanisms of gene expression, and the findings of this study are confirmatory of previously reported correlations. ${ }^{9,11}$

Inter-correlations between hepatic drug transporters included ABCC2/ABCC3 (Rs $=0.81, P=0.006 ; R^{2}$ $=0.12) ; \mathrm{SLC} 29 \mathrm{~A} 1 / \mathrm{SLC} 29 \mathrm{~A} 3\left(\mathrm{Rs}=0.78, \mathrm{P}=0.03 ; \mathrm{R}^{2}=0.48\right)$ and ABCC6/SLC22A9 (Rs $=0.81, \mathrm{P}=$ $\left.0.002 ; R^{2}=0.54\right)$. However, the number of sample pairs for strong and significant correlations was low $(n=7-12)$, which may require confirmation with higher numbers of samples. Only one of the uncovered correlations, $\mathrm{ABCC} 2 \mathrm{ABCC} 3$, was previously reported to be strong. ${ }^{44}$ Once confirmed, correlations of expression levels of enzymes and transporters can be used in more realistic simulations of drug 
clearance and drug-drug interactions, as demonstrated previously with several examples of CYP enzymes. ${ }^{45,46}$

\section{Evaluation of similarity between biological samples}

Similarity between biological replicates of the 23 biological samples was also evaluated looking at the proteome profiles using PIP and percentage identical proteins (PIPr) for all pairs of samples and the results are shown in Supplementary Figure 3. PIP varied between $41 \%$ and $66 \%$ and $\mathrm{PIPr}$ varied between $70 \%$ and $83 \%$ (Supplementary Table 3). Given the consistency in the methodology used, these variations are likely to reflect biological differences. Supplementary Figure 3 shows cluster analysis of data at both the peptide and protein levels, suggesting agreement between peptide and protein data, with two distinct clusters identified by hierarchical cluster analysis (HCA) and principal components analysis (PCA). The data form two clusters, but the relationship between the members of the clusters is, at this stage, unclear. There was no clear correlation with demographic and clinical data; although the small cluster contains largely younger, healthier individuals who were not taking any medication.

\section{DISCUSSION}

In contrast to targeted proteomics where only a pre-defined set of proteins can be quantified, label-free proteomics allows us to simultaneously quantify a large sub-set of the proteome in an individual, leading to a systems-level understanding of the cellular physiology. However, obtaining reproducible and accurate results using the label-free approach requires mass spectrometers capable of delivering high mass accuracy, liquid chromatography platforms able to deliver highly reproducible retention times and sophisticated software able to minimise technical variability by allowing accurate retention time alignment between multiple runs. ${ }^{17,18}$ In this study, the use of modern instrumentation with the above-mentioned 
capabilities along with improvements in sample preparation, has allowed the quantification of more than 2200 proteins in human liver microsomes including 45 proteins involved in the metabolism and transport of drugs and other xenobiotics. CYPs and UGTs are the proteins primarily involved in drug metabolism in the human liver. In this study, several CYPs and UGTs were found in the human liver microsomes. In agreement with published data, the highly expressed CYPs were CYP2E1, CYP2C9, CYP2C8,CYP3A4 and CYP2A6. $6,38-40$ In this study, CYP3A43, a well known drug-metabolising enzyme, was also measured but only in fewer than seven individuals. In agreement with published data, the most highly expressed UGT was UGT2B7, followed by UGT1A4, UGT2B4,UGT1A1 and UGT2B15. ${ }^{6-10,38,39}$ Where literature data are available the quantification of the $A B C$ and SLC transporters in this study is also in agreement. ${ }^{15,47,48}$

A number of drug metabolizing enzymes (CYPs $2 \mathrm{~A} 13$ and 4F12) and drug transporters (SLCs 16A2, 22A18, 29A3 and 31A1) were quantified for the first time. CYP2A13 is responsible for metabolic activation of many tobacco-specific carcinogens and similarly to CYP1A2 can also metabolise 4aminobiphenyl, phenacetin and aflatoxin B1.49 CYP4F12 can metabolise arachidonic acid and ebastine. ${ }^{50}$ SLC16A2 is known to have a profound physiological role in thyroid hormone transport and specific substrates for this transporter are thyroxine, diiodothyronine and triiodothyronine. ${ }^{51}$ SLC22A18 has a role in the transport of chloroquine and quinidine-related compounds. ${ }^{52}$ SLC31A1 is a copper transporter which mediates the flux of cisplatin and other platinum anti-cancer drugs. ${ }^{53}$ Finally, SLC29A3 is a transporter involved in mediating equilibrative diffusion of nucleoside drugs, such as cladribine, fludarabine, cytarabine and gemcitabine across the plasma membrane..$^{54}$ The ability to quantify novel targets such as those reported in this study is one of the primary advantages of label-free quantification methodology. 
In some previous studies, CYP4A11 was included in the quantified drug metabolizing enzymes, ${ }^{6,15}$ mainly because polymorphisms in CYP4A11 have been associated with hypertension/cardiovascular disease which can have an effect on choice of therapeutic drugs. ${ }^{55}$ In this study, although CYP4A11 was successfully quantified, it was not considered to be a drug metabolising enzyme. We also quantified several proteins, the polymorphisms of which are associated with several diseases, such as UGT1A1 (Gilbert's syndrome) and $A B C C 2$ (Dubin-Johnson syndrome), which in turn could affect the choice of therapeutic drugs prescribed. Some examples of proteins involved in disease development are shown in Supplementary Tables 8 (CYPs), 9 (UGTs), 10 (ABC transporters), and 11 (SLC transporters). However, further evaluation of these proteins is beyond the scope of this study.

The human liver microsomal samples used in this study have previously been used to quantify CYPs and UGTs using targeted proteomics approaches. Overall, there was good agreement in protein abundance measurements between the label-free approach used in the present study and the previous targeted proteomic approaches; nonetheless, the results are not identical.This can be due to several factors. First, label-free quantification assumes a uniform correlation between peptide peak intensity and its abundance, which is not true since different peptides present at the same concentration generate mass spectrometric signals of different intensities. ${ }^{12}$ The Hi-3 method can theoretically offset peptidespecific bias to some degree by using the median of the three most intense signals for each protein. Taking this into account, in contrast with targeted proteomics, label-free analysis is not intrinsically an absolute quantification strategy. Second, differences in abundance of proteins quantified using label-free and targeted proteomics may be affected by the proteins/peptides used as standards for quantification. In particular, the choice of signature peptides for targeted quantification of CYP, UGT and transporter proteins is challenging and relies on stringent criteria. We compared the peptides used for label-free analysis with those used for targeted quantification (where available) and there was limited overlap 
between the two sets (Supplementary Tables 13-15). In addition, appraisal of the set of peptides used for the global analysis indicated their suitability as surrogates. Most importantly, the discrepancies in observed protein abundances may well be driven by differences in workflows used for sample preparation (Supplementary Table 17) with no consensus on standardised methodology. In studies involving drug metabolism in the liver, protein abundances obtained from mass spectrometric analysis are normalised to the mass of liver microsomal fractions. However, the purity of microsomal fractions is not typically reported, which makes inter-laboratory comparisons of results quite challenging. Although only $19 \%$ of the results were within the bioequivalence range of 0.8 to 1.25 fold, ${ }^{43}$ which is extremely strict for this purpose, in the majority of cases ( $67 \%$ of all ratios), the two methods yielded a fold difference of less than $3 .{ }^{20}$ Analysis of the AFE and AAFE showed that the untargeted methodology gives systematically lower results than the targeted methods for UGTs but not for CYPs. In principle, we would expect targeted methodology to yield more accurate quantification, because the standards are simple isotopomers of the peptides being assessed, whereas untargeted methods rely on medians of dissimilar standards. In practice, poor choice of standards, transitions or molar ratio of standard to sample can compromise targeted measurements, and only the last of these applies to untargeted experiments. Both sets of measurements show good agreement with activity data, but the activity data is not based on absolute amounts of enzymes (CYPs or UGTs) so cannot be used to arbitrate between the proteomics measurements. Nevertheless, assessment of correlations between protein abundances estimated by the label-free and targeted aproaches indicated that the data were generally well-correlated, as shown in Supplementary Table 16.

The real advantage of label-free measurements, especially when acquired using state-of-the-art mass spectrometry, is that a very large number of proteins may be quantified simultaneously. The additional proteins include markers of different cell types and cellular components, enabling an assessment of the 
purity of biological samples, not immediately available by other methods. Human liver microsomes were, until recently, thought to be composed predominantly of endoplasmic reticulum from the parenchymal hepatocytes. ${ }^{56}$ Discrepancies in the total number detected in liver systems, as reported previously, ${ }^{15}$ may well be due to the nature of the system being analysed, with analyses of whole cell lysates generally identifying higher numbers of proteins compared to enriched fractions, such as microsomes. Other differences can be attributed to several methodological factors that can affect every step of the experimental workflow. Recently, it has been shown that microsomal fractions are typically heterogeneous, enriching endoplasmic reticulum but also proteins from other cellular compartments. ${ }^{29}$ The reliability of quantification of proteins of interest may therefore be compromised by variability in the levels of non-reticular proteins. On the positive side, the contamination by other cell types and cellular components was very consistent across these samples, ranging from $22 \%$ to $32 \%$. Label-free methodology is expected to be particularly powerful when microsomal preparations from different sources are compared. Cytosolic enzymes involved in drug-metabolism (e.g. sulfotransferases or glutathione transferases) were also detected in the microsomal fractions; however, since the cytosol represents a contaminant to microsomal preparations, these abundance data should be established in a more representative fraction, such as, cytosol or homogenate, in order for these data to be used in systems pharmacology modelling and extrapolation exercises.

Drug-metabolising enzymes and transporters have historically been quantified in units of pmol per milligram of microsomal protein. This is also the case in this manuscript. We have previously shown that varying expression of the most abundant proteins can affect the apparent abundance of the proteins involved in drug metabolism and transport, when expressed as pmol of protein per milligram of microsomal protein. ${ }^{29,37,57}$ We and others have therefore advocated the use of pmol per $\mathrm{g}$ tissue as a way of overcoming the effects of the most abundant proteins in the human liver microsomes on absolute 
quantification of the abundance of drug metabolising enzymes and transporters..$^{29,37,57}$ The present study points to a still more important reason for a change in unit - the possibility of varying amounts of contamination. There are, of course, limitations to using tissue mass as a standard for these measurements, although the literature is encouraging.

Simulations of drug trials rely on the use of scaling factors, including abundance levels, with realistic variability and correlations with clinical and demographic factors. ${ }^{5}$ Our data revealed large levels of interindividual variation across CYP enzymes (4- to 340-fold), UGT enzymes (5- to 70-fold), ABC transporters (7- to 200-fold) and SLC transporters (4- to 27-fold), highlighting the importance of elucidating and incorporating sources of variability. There were no significant sex-related differences in abundance of enzymes and transporters, consistent with a recent meta-analysis of CYP protein abundance. ${ }^{42}$ The overall trend of age-related decline in enzyme and transporter levels, although with no statistical significance in most cases, seemed to be a consistent observation, which requires further confirmation. The effect of age after maturation of expression has previously been reported to be minimal on abundance and activity of CYP enzymes per mass of liver. ${ }^{58-60}$ However, in vivo metabolic ratios analysis showed a decrease in whole liver metabolic capacity with age, mirroring the decline in renal function. ${ }^{61}$ These two observations can be explained by a decline in liver size to match body size decrease in older adults, ${ }^{62}$ accompanied by a decrease in the amount of liver protein per gram liver. ${ }^{63}$ Therefore, although the abundance levels normalized to microsomal protein content seem minimally affected, there are indications that whole liver content of such enzymes and transporters may be affected. This finding is corroborated by reduced drug hepatic clearance observed in older patients. ${ }^{64}$

Out of all the factors examined, genotype is perhaps the most clinically recognized covariate of expression and activity. The data in this study confirmed previously highlighted genotype-specific differences in the expression of CYP3A5 ${ }^{11,65}$ and CYP2D6. ${ }^{66}$ These differences in expression are 
expected to propagate to differences in enzymatic activity and therefore hepatic clearance of substrate drugs of these enzymes. In addition, our data suggest that higher body mass index (BMI) is consistent with a decline in the expression of enzymes and transporters, in line with recent evidence. ${ }^{67}$ This observation is consistent with the pro-inflammatory effect of obesity leading to decreased enzymatic and transporter activity. ${ }^{68}$ The analyzed set of samples was mostly from older obese or over-weight donors, which should be considered when using the generated data.

Although information related to expression covariates has the potential to improve the accuracy of predicting drug clearance and drug-drug interactions, it can be argued that these factors are still not utilized effectively. This highlights the importance of collecting data on very well-characterized populations, such as the present dataset. Another very useful aspect of abundance data that has recently been incorporated into modelling exercises is inter-correlations between individual proteins. ${ }^{45,46}$ The dataset uncovered several correlations that can be used to build more realistic systems pharmacology models, including the inter-correlations: CYP3A4/CYP3A5*1/*3,45 UGT1A4/UGT2B4, ${ }^{69}$ and $A B C C 2 / A B C C 3 .{ }^{44}$ These can also be confirmed at the mRNA level, ${ }^{70,71}$ which further support reports of common genetic regulation of expression of enzymes and transporters. It has been reported that drug transporter abundances quantified in microsomal fractions are frequently overestimated. To overcome this problem, the relative expression scaling factor (REF), which accounts the differences between the abundance of drug transporters in microsomal fractions with those in human hepatocytes, has been used to improve the accuracy of in vivo drug clearance for in vitro-in vivo extrapolation. ${ }^{36}$ Such approaches, when established, should enable more realistic predictions of the outcomes of therapy and better design of dosage regimens. ${ }^{29}$

\section{Conclusions}


We describe a label-free proteomic approach for the quantification of drug-metabolising enzymes and transporters in liver, based on high resolution mass spectrometry and rigorous data analysis. Validity of the data was confirmed against targeted proteomic data in matched samples and against enzyme catalytic activity. The method provides highly comprehensive information that can be used to ascertain the quality of samples, describe expression covariates, and cluster donors based on the primary analytes. The information obtained generally complements that of targeted proteomics, and the labelfree approach enabled quantification of two drug-metabolizing enzymes and four transporters for the first time. The pattern of expression supports the view that genotype, age and obesity (but not gender) affect the expression of several drug-metabolising enzymes and transporters. We expect that the use of this versatile label-free quantification approach will increase the availability of accurate and comprehensive protein abundance information, which will enhance prediction of drug efficacy and safety using computational models. This in turn will enable the optimisation of dosage of medicines given to patients to achieve maximal drug efficacy with limited toxicity. Considering the many existing gaps in QSP models, label-free proteomics offers a fast solution for simultaneous quantification of wide range of proteins as the first step which can, in time, be complemented by more targeted measurements.

\section{ASSOCIATED CONTENT}

\section{Supporting information}

Supplementary information contains demographic and clinic information from the liver donors, reproducibility data, comparative information of targeted and label-free proteomics for CYPs, UGTs and transporters, label-free quantification information for all identified CYPs, UGTs and transporters, and a compilation of sample preparation and analytical procedures used in diferent laboratories. The 
supplementary information also contains pictorial representation of the experimental workflow and principal component analysis data of biological reproducibility using PIP and PIPr.

\section{AUTHOR INFORMATION \\ Corresponding author: narciso.couto@manchester.ac.uk, ORCID ID: 0000-0001-7565-4357 and \\ jill.barber@manchester.ac.uk, ORCID ID:0000-0002-5424-0291}

\section{Author contributions}

This study was conceived by Narciso Couto, Zubida M. Al-Majdoub and Jill Barber. Narciso Couto and Zubida M. Al-Majdoub performed the experiments. Data analysis was performed by Narciso Couto, Zubida M. Al-Majdoub, Brahim Achour and Jill Barber. All authors contributed to the writing of the manuscript (Narciso Couto, Zubida M. Al-Majdoub, Brahim Achour, Phillip C. Wright, Amin RostamiHodjegan and Jill Barber).

\section{Conflict of interests}

The authors declare no competing financial interest.

\section{ACKNOWLEDGEMENTS}

The authors thank Pfizer (Groton, CT) for providing HLM samples along with demographic, clinical and enzymatic activity data; the ChELSI Institute, University of Sheffield, for access to LC-MS/MS 
instrumentation (funded under BBSRC grant: BB/M012166/1; and EPSRC grant:EP/E036252/1); and the Bio-MS core facility, University of Manchester, for access to Progenesis software. We also thank Dr. Anna Vildhede (AstraZeneca) for providing label-free data from her study.

\section{ABBREVIATIONS}

ABC, ATP-binding cassette; ADME, absorption, distribution, metabolism and elimination; AQUA, absolute quantification; BSA, bovine serum albumin; CYP, cytochrome P450; DDI, drug-drug interaction; FASP, filter-aided sample preparation; HLM, human liver microsomes; IVIVE, in vitro-in vivo extrapolation; LC-MS/MS, liquid chromatography-tandem mass spectrometry; PBPK, physiologicallybased pharmacokinetics, QconCAT, quantification concatemer; SLC, solute carrier; UGT, uridine 5'diphosphate-glucuronosyltransferase; UPLC, ultra-performance liquid chromatography

\section{REFERENCES}

(1) Jamei, M. Recent Advances in Development and Application of Physiologically-Based Pharmacokinetic (PBPK) Models: A Transition from Academic Curiosity to Regulatory Acceptance. Current Pharmacology Reports. 2016, pp 161-169.

(2) Rostami-Hodjegan, A. Physiologically Based Pharmacokinetics Joined With In Vitro-In Vivo Extrapolation of ADME: A Marriage Under the Arch of Systems Pharmacology. Clin. Pharmacol. 
Ther. 2012, 92 (1), 50-61.

(3) August, O.; Pharmacokinetic, B. Program of physiologically-based pharmacokinetic and pharmacodynamic modeling (PBPK Program).

(4) Turner, R. M.; Park, B. K.; Pirmohamed, M. Parsing Interindividual Drug Variability: An Emerging Role for Systems Pharmacology. Wiley Interdisciplinary Reviews: Systems Biology and Medicine. 2015, pp 221-241.

(5) Rostami-Hodjegan, A.; Tucker, G. T. Simulation and Prediction of in Vivo Drug Metabolism in Human Populations from in Vitro Data. Nature Reviews Drug Discovery. 2007, pp 140-148.

(6) Ohtsuki, S.; Schaefer, O.; Kawakami, H.; Inoue, T.; Liehner, S.; Saito, A.; Ishiguro, N.; Kishimoto, W.; Ludwig-Schwellinger, E.; Ebner, T.; et al. Simultaneous Absolute Protein Quantification of Transporters, Cytochromes P450, and UDP-Glucuronosyltransferases as a Novel Approach for the Characterization of Individual Human Liver: Comparison with MRNA Levels and Activities. Drug Metab. Dispos. 2012, 40 (1), 83-92.

(7) Sato, Y.; Nagata, M.; Tetsuka, K.; Tamura, K.; Miyashita, A.; Kawamura, A.; Usui, T. Optimized Methods for Targeted Peptide-Based Quantification of Human Uridine 5'-DiphosphateGlucuronosyltransferases in Biological Specimens Using Liquid Chromatography-Tandem Mass Spectrometry. Drug Metab. Dispos. 2014, 42 (5), 885-889.

(8) Harbourt, D. E.; Fallon, J. K.; Ito, S.; Baba, T.; Ritter, J. K.; Glish, G. L.; Smith, P. C. Quantification of Human Uridine-Diphosphate Glucuronosyl Transferase 1A Isoforms in Liver, Intestine, and Kidney Using Nanobore Liquid Chromatography-Tandem Mass Spectrometry. Anal. Chem. 2012, $84(1), 98-105$. 
(9) Margaillan, G.; Rouleau, M.; Klein, K.; Fallon, J. K.; Caron, P.; Villeneuve, L.; Smith, P. C.; Zanger, U. M.; Guillemette, C. Multiplexed Targeted Quantitative Proteomics Predicts Hepatic Glucuronidation Potential. Drug Metab. Dispos. 2015, 43 (9), 1331-1335.

(10) Fallon, J. K.; Neubert, H.; Hyland, R.; Goosen, T. C.; Smith, P. C. Targeted Quantitative Proteomics for the Analysis of 14 UGT1As and -2Bs in Human Liver Using NanoUPLC-MS/MS with Selected Reaction Monitoring. J. Proteome Res. 2013, 12 (10), 4402-4413.

(11) Achour, B.; Russell, M. R.; Barber, J.; Rostami-Hodjegan, A. Simultaneous Quantification of the Abundance of Several Cytochrome P450 and Uridine 5'-Diphospho-Glucuronosyltransferase Enzymes in Human Liver Microsomes Using Multiplexed Targeted Proteomics. Drug Metab. Dispos. 2014, 42 (4), 500-510.

(12) Couto, N.; Barber, J.; Gaskell, S. J. Matrix-Assisted Laser Desorption/lonisation Mass Spectrometric Response Factors of Peptides Generated Using Different Proteolytic Enzymes. J. Mass Spectrom. 2011, 46 (12), 1233-1240.

(13) Wegler, C.; Gaugaz, F. Z.; Andersson, T. B.; Wiśniewski, J. R.; Busch, D.; Gröer, C.; Oswald, S.; Norén, A.; Weiss, F.; Hammer, H. S.; et al. Variability in Mass Spectrometry-Based Quantification of Clinically Relevant Drug Transporters and Drug Metabolizing Enzymes. Mol. Pharm. 2017, 14 (9), 3142-3151.

(14) Wiśniewski, J. R.; Zougman, A.; Nagaraj, N.; Mann, M. Universal Sample Preparation Method for Proteome Analysis. Nat. Methods 2009, 6 (5), 359-362.

(15) Vildhede, A.; Wiśniewski, J. R.; Norén, A.; Karlgren, M.; Artursson, P. Comparative Proteomic Analysis of Human Liver Tissue and Isolated Hepatocytes with a Focus on Proteins Determining 
Drug Exposure. J. Proteome Res. 2015, 14 (8), 3305-3314.

(16) Al Feteisi, H.; Achour, B.; Barber, J.; Rostami-Hodjegan, A. Choice of LC-MS Methods for the Absolute Quantification of Drug-Metabolizing Enzymes and Transporters in Human Tissue: A Comparative Cost Analysis. AAPS J. 2015, 17 (12), 438-446.

(17) Neilson, K. A.; Ali, N. A.; Muralidharan, S.; Mirzaei, M.; Mariani, M.; Assadourian, G.; Lee, A.; Van Sluyter, S. C.; Haynes, P. A. Less Label, More Free: Approaches in Label-Free Quantitative Mass Spectrometry. Proteomics 2011, 11 (4), 535-553.

(18) Megger, D. A.; Bracht, T.; Meyer, H. E.; Sitek, B. Label-Free Quantification in Clinical Proteomics. Biochim. Biophys. Acta - Proteins Proteomics 2013, 1834 (8), 1581-1590.

(19) Wiśniewski, J. R.; Wegler, C.; Artursson, P. Multiple-Enzyme-Digestion Strategy Improves Accuracy and Sensitivity of Label- and Standard-Free Absolute Quantification to a Level That Is Achievable by Analysis with Stable Isotope-Labeled Standard Spiking. J. Proteome Res. 2018, acs.jproteome.8b00549.

(20) Achour, B.; Dantonio, A.; Niosi, M.; Novak, J. J.; Fallon, J. K.; Barber, J.; Smith, P. C.; RostamiHodjegan, A.; Goosen, T. C. Quantitative Characterization of Major Hepatic UDPGlucuronosyltransferase Enzymes in Human Liver Microsomes: Comparison of Two Proteomic Methods and Correlation with Catalytic Activity. Drug Metab. Dispos. 2017, 45 (10), 1102-1112.

(21) Langenfeld, E.; Zanger, U. M.; Jung, K.; Meyer, H. E.; Marcus, K. Mass Spectrometry-Based Absolute Quantification of Microsomal Cytochrome P450 2D6 in Human Liver. Proteomics 2009, 9 (9), 2313-2323. 
(22) Bradford, M. M. A Rapid and Sensitive Method for the Quantitation of Microgram Quantities of Protein Utilizing the Principle of Protein-Dye Binding. Anal. Biochem. 1976, 72 (1-2), 248-254.

(23) Al Feteisi, H.; Al-Majdoub, Z. M.; Achour, B.; Couto, N.; Rostami-Hodjegan, A.; Barber, J. Identification and Quantification of Blood-Brain Barrier Transporters in Isolated Rat Brain Microvessels. J. Neurochem. 2018, 44, 10.1111/jnc.14446.

(24) Silva, J. C. Absolute Quantification of Proteins by LCMSE: A Virtue of Parallel Ms Acquisition. Mol. Cell. Proteomics 2005, 5 (1), 144-156.

(25) Achour, B.; Dantonio, A.; Niosi, M.; Novak, J. J.; Al-Majdoub, Z. M.; Goosen, T. C.; RostamiHodjegan, A.; Barber, J. Data Generated by Quantitative Liquid Chromatography-Mass Spectrometry Proteomics Are Only the Start and Not the Endpoint: Optimization of Quantitative Concatemer-Based Measurement of Hepatic Uridine-5'-Diphosphate-Glucuronosyltransferase Enzymes with Ref. Drug Metab. Dispos. 2018, 46 (6), 805-812.

(26) Walsky, R. L.; Obach, R. S. Validated Assays for Human Cytochrome P450 Activities. Drug Metab. Dispos. 2004, 32 (6), 647-660.

(27) Walsky, R. L.; Obach, R. S.; Hyland, R.; Kang, P.; Zhou, S.; West, M.; Geoghegan, K. F.; Helal, C. J.; Walker, G. S.; Goosen, T. C.; et al. Selective Mechanism-Based Inactivation of CYP3A4 by CYP3cide (PF-04981517) and Its Utility as an in Vitro Tool for Delineating the Relative Roles of CYP3A4 versus CYP3A5 in the Metabolism of Drugs. Drug Metab. Dispos. 2012, 40 (9), 16861697.

(28) Walsky, R. L.; Bauman, J. N.; Bourcier, K.; Giddens, G.; Lapham, K.; Negahban, A.; Ryder, T. F.; Obach, R. S.; Hyland, R.; Goosen, T. C. Optimized Assays for Human UDP- 
Glucuronosyltransferase (UGT) Activities: Altered Alamethicin Concentration and Utility to Screen for UGT Inhibitors. Drug Metab. Dispos. 2012, 40 (5), 1051-1065.

(29) Achour, B.; Al Feteisi, H.; Lanucara, F.; Rostami-Hodjegan, A.; Barber, J. Global Proteomic Analysis of Human Liver Microsomes: Rapid Characterization and Quantification of Hepatic DrugMetabolizing Enzymes. Drug Metab. Dispos. 2017, 45 (6), 666-675.

(30) Neufeld, C.; Filipp, F. V.; Simon, B.; Neuhaus, A.; Schüller, N.; David, C.; Kooshapur, H.; Madl, T.; Erdmann, R.; Schliebs, W.; et al. Structural Basis for Competitive Interactions of Pex14 with the Import Receptors Pex5 and Pex19. EMBO J. 2009, 28 (6), 745-754.

(31) Rak, M.; Bénit, P.; Chrétien, D.; Bouchereau, J.; Schiff, M.; El-Khoury, R.; Tzagoloff, A.; Rustin, P. Mitochondrial Cytochrome c Oxidase Deficiency. Clin. Sci. (Lond). 2016, 130 (6), 393-407.

(32) Prior, K. K.; Wittig, I.; Leisegang, M. S.; Groenendyk, J.; Weissmann, N.; Michalak, M.; JansenDürr, P.; Shah, A. M.; Brandes, R. P. The Endoplasmic Reticulum Chaperone Calnexin Is a NADPH Oxidase NOX4 Interacting Protein. J. Biol. Chem. 2016, 291 (13), 7045-7059.

(33) Peters, D. T.; Henderson, C. A.; Warren, C. R.; Friesen, M.; Xia, F.; Becker, C. E.; Musunuru, K.; Cowan, C. A. Asialoglycoprotein Receptor 1 is a Specific Cell-Surface Marker for Isolating Hepatocytes Derived from Human Pluripotent Stem Cells. Development 2016, 143 (9), 1475-1481.

(34) Harris, R. L.; van den Berg, C. W.; Bowen, D. J. ASGR1 and ASGR2, the Genes That Encode the Asialoglycoprotein Receptor (Ashwell Receptor), Are Expressed in Peripheral Blood Monocytes and Show Interindividual Differences in Transcript Profile. Mol. Biol. Int. 2012, 2012, 1-10.

(35) Miller, C. M.; Donner, A. J.; Blank, E. E.; Egger, A. W.; Kellar, B. M.; Østergaard, M. E.; Seth, P. 
P.; Harris, E. N. Stabilin-1 and Stabilin-2 Are Specific Receptors for the Cellular Internalization of Phosphorothioate-Modified Antisense Oligonucleotides (ASOs) in the Liver. Nucleic Acids Res. 2016, 44 (6), 2782-2794.

(36) Vildhede, A.; Nguyen, C.; Erickson, B. K.; Kunz, R. C.; Jones, R.; Kimoto, E.; Bourbonais, F.; Rodrigues, A. D.; Varma, M. V. S. Comparison of Proteomic Quantification Approaches for Hepatic Drug Transporters: Multiplexed Global Quantitation Correlates with Targeted Proteomic Quantitation. Drug Metab. Dispos. 2018, 46 (5), 692-696.

(37) Drozdzik, M.; Busch, D.; Lapczuk, J.; Müller, J.; Ostrowski, M.; Kurzawski, M.; Oswald, S. Protein Abundance of Clinically Relevant Drug-Metabolizing Enzymes in the Human Liver and Intestine: A Comparative Analysis in Paired Tissue Specimens. Clin. Pharmacol. Ther. 2018, 104 (3), 515524.

(38) Achour, B.; Russell, M. R.; Barber, J.; Rostami-Hodjegan, A. Simultaneous Quantification of the Abundance of Several Cytochrome P450 and Uridine 5'-Diphospho-Glucuronosyltransferase Enzymes in Human Liver Microsomes Using Multiplexed Targeted Proteomics. Drug Metab. Dispos. 2014, 42 (4), 500-510.

(39) Asha, S.; Vidyavathi, M. Role of Human Liver Microsomes in In Vitro Metabolism of Drugs-A Review. Appl. Biochem. Biotechnol. 2010, 160 (6), 1699-1722.

(40) Zhang, H.-F.; Li, Z.-H.; Liu, J.-Y.; Liu, T.-T.; Wang, P.; Fang, Y.; Zhou, J.; Cui, M.-Z.; Gao, N.; Tian, X.; et al. Correlation of Cytochrome P450 Oxidoreductase Expression with the Expression of 10 Isoforms of Cytochrome P450 in Human Liver. Drug Metab. Dispos. 2016, 44 (8), 1193-1200.

(41) Achour, B.; Rostami-Hodjegan, A.; Barber, J. Protein Expression of Various Hepatic Uridine 5'- 
Diphosphate Glucuronosyltransferase (UGT) Enzymes and Their Inter-Correlations: A MetaAnalysis. Biopharm. Drug Dispos. 2014, 34 (6), 353-361.

(42) Achour, B.; Barber, J.; Rostami-Hodjegan, A. Expression of Hepatic Drug-Metabolizing Cytochrome P450 Enzymes and Their Intercorrelations: A Meta-Analysis. Drug Metab. Dispos. 2014, $42(8), 1349-1356$.

(43) Davit, B. M.; Nwakama, P. E.; Buehler, G. J.; Conner, D. P.; Haidar, S. H.; Patel, D. T.; Yang, Y.; Yu, L. X.; Woodcock, J. Comparing Generic and Innovator Drugs: A Review of 12 Years of Bioequivalence Data from the United States Food and Drug Administration. Ann. Pharmacother. 2009, 43 (10), 1583-1597.

(44) Mooij, M. G.; van de Steeg, E.; Van Rosmalen, J.; Windster, J. D.; de Koning, B. A. E.; Vaes, W. H.; van Groen, B. D.; Tibboel, D.; Wortelboer, H. M.; de Wildt, S. N. Proteomic Analysis of the Developmental Trajectory of Human Hepatic Membrane Transporter Proteins in the First Three Months of Life. Drug Metab. Dispos. 2016, No. July, 1005-1013.

(45) Barter, Z. E.; Perrett, H. F.; Yeo, K. R.; Allorge, D.; Lennard, M. S.; Rostami-Hodjegan, A. Determination of a Quantitative Relationship between Hepatic CYP3A5*1/*3 and CYP3A4 Expression for Use in the Prediction of Metabolic Clearance in Virtual Populations. Biopharm. Drug Dispos. 2010, 31 (8-9), 516-532.

(46) Doki, K.; Darwich, A. S.; Achour, B.; Tornio, A.; Backman, J. T.; Rostami-Hodjegan, A. Implications of Intercorrelation between Hepatic CYP3A4-CYP2C8 Enzymes for the Evaluation of Drug-Drug Interactions: A Case Study with Repaglinide. Br. J. Clin. Pharmacol. 2018, 84 (5), 972-986.

(47) Prasad, B.; Evers, R.; Gupta, A.; Hop, C. E. C. A.; Salphati, L.; Shukla, S.; Ambudkar, S. V.; 
Unadkat, J. D. Interindividual Variability in Hepatic Organic Anion-Transporting Polypeptides and P-Glycoprotein (ABCB1) Protein Expression: Quantification by Liquid Chromatography Tandem Mass Spectroscopy and Influence of Genotype, Age, and Sex. Drug Metab. Dispos. 2014, 42 (1), 78-88.

(48) Fallon, J. K.; Smith, P. C.; Xia, C. Q.; Kim, M. S. Quantification of Four Efflux Drug Transporters in Liver and Kidney Across Species Using Targeted Quantitative Proteomics by Isotope Dilution NanoLC-MS/MS. Pharm. Res. 2016, 33 (9), 2280-2288.

(49) Tsuyosh, F. T. N. M. H. S. H. M. K. Y. CYP2A13 Metabolizes the Substrates of Human CYP1A2, Phenacetin, and Theophylline. Drug Metab. Dispos. 2007, 35 (3), 335-339.

(50) Hashizume, T. Involvement of CYP2J2 and CYP4F12 in the Metabolism of Ebastine in Human Intestinal Microsomes. J. Pharmacol. Exp. Ther. 2002, 300 (1), 298-304.

(51) Bernal, J.; Guadaño-Ferraz, A.; Morte, B. Thyroid Hormone Transporters-Functions and Clinical Implications. Nat. Rev. Endocrinol. 2015, 11 (7), 406-417.

(52) Ito, S.; Fujino, Y.; Ogata, S.; Hirayama-Kurogi, M.; Ohtsuki, S. Involvement of an Orphan Transporter, SLC22A18, in Cell Growth and Drug Resistance of Human Breast Cancer MCF7 Cells. J. Pharm. Sci. 2018, 107 (12), 3163-3170.

(53) Fung, K. L.; Tepede, A. K.; Pluchino, K. M.; Pouliot, L. M.; Pixley, J. N.; Hall, M. D.; Gottesman, M. M. Uptake of Compounds That Selectively Kill Multidrug-Resistant Cells: The Copper Transporter SLC31A1 (CTR1) Increases Cellular Accumulation of the Thiosemicarbazone NSC73306. Mol. Pharm. 2014, 11 (8), 2692-2702. 
(54) King, A. E.; Ackley, M. A.; Cass, C. E.; Young, J. D.; Baldwin, S. A. Nucleoside Transporters: From Scavengers to Novel Therapeutic Targets. Trends Pharmacol. Sci. 2006, 27 (8), 416-425.

(55) Polonikov, A.; Sirotina, S.; Ponomarenko, I.; Shvetsov, Y.; Bykanova, M.; Bocharova, A.; Vagaytseva, K.; Stepanov, V.; Solodilova, M. AB074. Genetic Variation in CYP2U1, CYP4A11 and CYP4F2 Involved in the Biosynthesis of Hydroxyeicosatetraenoic Acids and Susceptibility to Hypertension and Atherosclerosis of Various Locations. Ann. Transl. Med. 2017, 5 (S2), AB074AB074.

(56) Hewitt, N. J.; Lechón, M. J. G.; Houston, J. B.; Hallifax, D.; Brown, H. S.; Maurel, P.; Kenna, J. G.; Gustavsson, L.; Lohmann, C.; Skonberg, C.; et al. Primary Hepatocytes: Current Understanding of the Regulation of Metabolic Enzymes and Transporter Proteins, and Pharmaceutical Practice for the Use of Hepatocytes in Metabolism, Enzyme Induction, Transporter, Clearance, and Hepatotoxicity Studies. Drug Metabolism Reviews. 2007, pp 159-234.

(57) Prasad, B.; Bhatt, D. K.; Johnson, K.; Chapa, R.; Chu, X.; Salphati, L.; Xiao, G.; Lee, C.; Hop, C. E. C. A.; Mathias, A.; et al. Abundance of Phase 1 and 2 Drug-Metabolizing Enzymes in Alcoholic and Hepatitis C Cirrhotic Livers: A Quantitative Targeted Proteomics Study. Drug Metab. Dispos. 2018, 46 (7), 943-952.

(58) Wolbold, R.; Klein, K.; Burk, O.; Nüssler, A. K.; Neuhaus, P.; Eichelbaum, M.; Schwab, M.; Zanger, U. M. Sex Is a Major Determinant of CYP3A4 Expression in Human Liver. Hepatology 2003, 38, 978-988.

(59) Galetin, A.; Brown, C.; Hallifax, D.; Ito, K.; Houston, J. B. Utility of Recombinant Enzyme Kinetics in Prediction of Human Clearance: Impact of Variability, CYP3A5, and CYP2C19 on CYP3A4 
Probe Substrates. Drug Metab. Dispos. 2004, 32 (12), 1411-1420.

(60) King, B. P.; Leathart, J. B. S.; Mutch, E.; Williams, F. M.; Daly, A. K. CYP3A5 Phenotype-Genotype Correlations in a British Population. Br. J. Clin. Pharmacol. 2003, 55 (6), 625-629.

(61) Rostami-Hodjegan, A.; Kroemer, H. K.; Tucker, G. T. In-Vivo Indices of Enzyme Activity: The Effect of Renal Impairment on the Assessment of CYP2D6 Activity. Pharmacogenetics 1999, 9 (3), 277286.

(62) Johnson, T. N.; Tucker, G. T.; Tanner, M. S.; Rostami-Hodjegan, A. Changes in Liver Volume from Birth to Adulthood: A Meta-Analysis. Liver Transplant. 2005, 11 (11), 1481-1493.

(63) Barter, Z. E.; Chowdry, J. E.; Harlow, J. R.; Snawder, J. E.; Lipscomb, J. C.; Rostami-Hodjegan, A. Covariation of Human Microsomal Protein per Gram of Liver with Age: Absence of Influence of Operator and Sample Storage May Justify Interlaboratory Data Pooling. Drug Metab. Dispos. 2008, 36 (12), 2405-2409.

(64) Polasek, T. M.; Patel, F.; Jensen, B. P.; Sorich, M. J.; Wiese, M. D.; Doogue, M. P. Predicted Metabolic Drug Clearance with Increasing Adult Age. Br. J. Clin. Pharmacol. 2013, 75 (4), 10191028.

(65) Westlind-Johnsson, A.; Malmebo, S.; Johansson, A.; Otter, C.; Andersson, T. B.; Johansson, I.; Edwards, R. J.; Boobis, A. R.; Ingelman-Sundberg, M. Comparative Analysis of CYP3A Expression in Human Liver Suggests Only a Minor Role for CYP3A5 in Drug Metabolism. Drug Metab. Dispos. 2003, $31(6), 755-761$.

(66) Zanger, U. M.; Fischer, J.; Raimundo, S.; Stüven, T.; Evert, B. O.; Schwab, M.; Eichelbaum, M. 
Comprehensive Analysis of the Genetic Factors Determining Expression and Function of Hepatic CYP2D6. Pharmacogenetics 2001, 11, 573-585.

(67) EMA. Reflection Paper on Investigation of Pharmacokinetics and Pharmacodynamics in the Obese Population. 2018, $44(0), 1-11$.

(68) Morgan, E. T. Impact of Infectious and Inflammatory Disease on Cytochrome P450-Mediated Drug Metabolism and Pharmacokinetics. Clin. Pharmacol. Ther. 2009, 85 (4), 434-438.

(69) Margaillan, G.; Rouleau, M.; Klein, K.; Fallon, J. K.; Caron, P.; Villeneuve, L.; Smith, P. C.; Zanger, U. M.; Guillemette, C. Multiplexed Targeted Quantitative Proteomics Predicts Hepatic Glucuronidation Potential. Drug Metab. Dispos. 2015, 43 (9), 1331-1335.

(70) Wortham, M.; Czerwinski, M.; He, L.; Parkinson, A.; Wan, Y. J. Y. Expression of Constitutive Androstane Receptor, Hepatic Nuclear Factor 4a, and P450 Oxidoreductase Genes Determines Interindividual Variability in Basal Expression and Activity of a Broad Scope of Xenobiotic Metabolism Genes in the Human Liver. Drug Metab. Dispos. 2007, 35 (9), 1700-1710.

(71) Izukawa, T.; Nakajima, M.; Fujiwara, R.; Yamanaka, H.; Fukami, T.; Takamiya, M.; Aoki, Y.; Ikushiro, S.; Sakaki, T.; Yokoi, T. Quantitative Analysis of UGT1A and UGT2B Expression Levels in Human Livers. Drug Metab. Dispos. 2009, 37 (8), 1759-1768.

\section{FIGURE LEGENDS}

Figure 1 Global proteomic analysis of human liver microsomes ( $n=23$ samples), showing the subcellular localization of identified proteins (A), and the origin of the 20 most abundantly expression proteins 
mapped along with cell and organelle markers $(B)$, showing that this fraction is contaminated due to presence of different cell types (Cell markers; ASGR1/2: hepatocytes, STAB1/2: liver endothelial cells) and co-sedimentation of several cellular components (Organelle markers; CANX: endoplasmic reticulum, ATP1A1/CD81: plasma membrane, COX4: mitochondria, PEX14: peroxisomes); the 20 most abundant proteins were of three origins: reticular, mitochondrial and cytoplasmic/cytosolic. The cumulative amount of the quantified proteins $(C)$, representing assessment of purity of the microsomal fraction, shows contribution of the 20 most highly abundant proteins to total protein amount (22\%-32\%). A large number of drug and xenobiotic metabolizing and transporting proteins were identified in the HLM samples (D), amongst which cytochrome P450 enzymes, UGTs, ABC and SLC transporters (E) are of particular interest. In A, the numbers of proteins in each sub-cellular component is shown along with percentage contribution to the total number of proteins; these percentages add up to more than $100 \%$ due to expression of several proteins in more than one sub-cellular location. ABC, ATP-binding cassette transporters; CYP, cytochrome P450 enzymes; DME, drug/xenobiotic metabolizing enzymes; ER, endoplasmic reticulum; PM, plasma membrane; SLC, solute carrier transporters; UGT, uridine 5'diphospho-glucuronosyltransferases.

Figure 2 Scatter plots and pie charts representing the abundance of drug-metabolizing cytochrome P450 $(A, C)$ and UGT (B, D) enzymes; scatter plots of the abundance of $A B C(E)$ and SLC (F) drug transporters; and bar chart of the numbers of quantified enzymes and transporters involved in the metabolism and transport of drugs and endogenous compounds (G). In A, B, E and $F$, the red bars represent mean abundance levels expressed in picomoles per milligram microsomal protein. In G, CYP, cytochrome P450 enzymes; UGT, uridine 5'-diphospho-glucuronosyltransferases; ABC, ATP-binding cassette transporters; SLC, solute carrier transporters; drug and endogenous refer to substrates of enzymes and transporters. 
Figure 3 Comparison of abundance values measured using the label-free strategy relative to two targeted methods (AQUA and QconCAT) for cytochrome P450 enzymes (A and B) and UDPglucuronosyltransferases $(C$ and $D)$ in matched liver microsomal samples $(n=21)$. In A and $C$, enzyme abundances are shown as box and whiskers plots with the whiskers representing the ranges, the boxes representing the $25^{\text {th }}$ and $75^{\text {th }}$ centiles, the lines showing the medians and the + signs denoting the means. Mann-Whitney tests were used to assess differences with statistically significant discrepancies shown; *, $\mathrm{P}<0.05 ;{ }^{* *}, \mathrm{P}<0.01 ;{ }^{* *}, \mathrm{P}<0.001$. In $\mathrm{B}$ and $\mathrm{D}$, fold error values are plotted as a frequency distribution showing lower values generated by label-free quantification. Fold errors are calculated as $x_{1} / x_{2}$ ratios for label free measurements $\left(x_{1}\right)$ relative to targeted measurements $\left(x_{2}\right)$ using either QconCAT (C) or AQUA and QconCAT (D). The light-blue shaded area indicates values within 3-fold, considered as generally interchangeable. AFE, average fold error; AAFE, absolute average fold error; abundance levels are expressed in picomoles per milligram HLM protein.

Figure 4 Correlation of the abundance levels of cytochrome P450 (A) and uridine 5'-diphosphoglucuronosyltransferase enzymes (B) measured using label-free global proteomics against catalytic activity. Strong and significant correlations $(R s>0.70, P<0.008)$ with very limited scatter $\left(R^{2}>0.50\right)$ are shown in red; moderate correlations $(R s>0.50, P<0.008)$ with limited scatter $\left(R^{2}>0.30\right)$ are shown in blue. CYP substrates: CYP1A2 (phenacetin), CYP2B6 (bupropion), CYP2C9 (diclofenac), CYP2C19 (Smephenytoin), CYP2D6 (bufuralol), CYP3A4 (testosterone), CYP3A5 (midazolam). UGT substrates: UGT1A1 ( $\beta$-estradiol), UGT1A3 (chenodeoxycholic acid), UGT1A4 (trifluoperazine), UGT1A6 (5hydroxytryptophol), UGT1A9 (propofol), UGT2B7 (zidovudine), UGT2B15 (S-oxazepam). Abundance is measured in units of picomoles enzyme per milligram microsomal protein, and activity is measured in units of nanomoles per minute per milligram microsomal protein. The CYP3A5 activity was measured in the presence of a CYP3cide to silence CYP3A4. 
Figure 5 Covariates of expression of hepatic cytochrome P450 and UGT enzymes measured using the label-free proteomic strategy. The variables assessed were sex (A, B), age (C), genotype (D) and body mass index, BMI (E). Sex did not affect expression with no significant differences between male and female donors (A and B). An overall declining trend with age was observed for all enzymes, with little statistical significance except for a few UGT examples (C). Genotype was a significant factor for CYP3A5 expression with ${ }^{*} 1 /{ }^{*} 3$ genotype being expressed at higher levels than ${ }^{*} 3 / 3$ ( 16 -fold higher). Only borderline significant difference in expression was seen between CYP2D6 genotypes (C). There was an overall declining trend of expression with BMI with differences of expression observed between normal weight, overweight and moderately obese patients (D) assessed using ANOVA and Mann-Whitney test for group and pairwise analysis. In A, B and D, abundance data are presented as mean \pm SD. In $C$, Rs is Spearman rank-order correlation coefficient. In $\mathrm{E}$, the boxes are the $25^{\text {th }}$ and $75^{\text {th }}$ centiles, the whiskers are the ranges, the lines are the medians and the + signs are the means. The scale inset on the right is the BMI scale for the three categories (normal: BMI 18.5-25; overweight: BMI 25-30; obese: BMI > $30 \mathrm{~kg}$ $\left.\mathrm{m}^{-2}\right) ;{ }^{*}, \mathrm{P}<0.05 ;{ }^{* *}, \mathrm{P}<0.01 ;{ }^{* * *}, \mathrm{P}<0.001$

Figure 6 Heat maps showing the abundance levels of drug metabolizing cytochrome P450 (A) and UDPglucuronosyltransferase (B) enzymes in the microsomal samples. Cluster generation was based on rankorder correlation of normal log-transformed expression data. Blue shows low abundances and red high abundances. The red shaded boxes denote the main correlation clusters in the two enzyme families. Examples of significant correlations within CYP and UGT data are shown in panels (C) and (D), respectively. Strong correlations are shown in red and moderate ones in blue. Correlation statistics are provided in Supporting Information. Abundance levels are expressed in picomoles per milligram HLM protein. 


\section{TABLES}

Table 1 - Expression levels of 17 cytochrome P450 (CYP) enzymes, NADPH-cytochrome P450 reductase (POR) and cytochrome- $b_{5}$ (CYB5A), with known involvement in drug modification pathways in human liver microsomal fractions. Protein expression is represented by the median, the median absolute deviation (MAD), the mean, the standard deviation of the mean (SD), the coefficient of variation (CV) and the range ( $\min -\max$ ). Proteins highlighted in blue have been quantified for the first time in this study. Abundance of CYPs is expressed in pmol $\mathrm{mg}^{-1}$ of liver microsomal protein.

\begin{tabular}{|c|c|c|c|c|c|c|}
\hline & Median & $M A D^{a}$ & Mean $\pm S D^{b}$ & $C V$ & Range & $n^{d}$ \\
\hline Enzyme & $\mathrm{pmol} \mathrm{mg}^{-1}$ & pmol mg ${ }^{-1}$ & pmol mg-1 & $\%$ & $\begin{array}{c}(\min -\max ) \\
p m o l m^{-1}\end{array}$ & \\
\hline CYP1A2 & 11.31 & 4.80 & $14.14 \pm 13.02$ & 92.08 & $1.11-56.42$ & 23 \\
\hline CYP2A6 & 23.19 & 13.80 & $25.62 \pm 19.41$ & 75.78 & $0.71-69.68$ & 21 \\
\hline CYP2A13 & 1.50 & 0.80 & $2.07 \pm 2.07$ & 100.15 & $0.04-5.32$ & 7 \\
\hline CYP2B6 & 5.36 & 3.40 & $6.78 \pm 5.99$ & 88.41 & $0.48-22.63$ & 23 \\
\hline CYP2C8 & 24.59 & 15.90 & $29.78 \pm 18.65$ & 62.61 & $4.18-67.52$ & 23 \\
\hline CYP2C9 & 32.60 & 10.60 & $37.53 \pm 20.67$ & 55.08 & $8.49-87.20$ & 23 \\
\hline CYP2C18 & 0.55 & 0.30 & $1.60 \pm 2.44$ & 152.83 & $0.12-9.66$ & 20 \\
\hline CYP2C19 & 1.38 & 1.10 & $3.43 \pm 3.59$ & 104.49 & $0.15-11.62$ & 17 \\
\hline CYP2D6 & 4.44 & 2.40 & $6.05 \pm 5.11$ & 84.49 & $1.74-20.54$ & 15 \\
\hline CYP2E1 & 50.69 & 15.00 & $54.38 \pm 24.67$ & 45.36 & $26.94-127.26$ & 23 \\
\hline CYP2J2 & 0.53 & 0.10 & $0.64 \pm 0.43$ & 66.97 & $0.11-1.59$ & 17 \\
\hline CYP3A4 & 25.46 & 11.20 & $28.52 \pm 20.67$ & 72.47 & $2.58-93.71$ & 23 \\
\hline CYP3A5 & 5.80 & 5.20 & $8.63 \pm 9.51$ & 110.24 & $0.19-27.78$ & 23 \\
\hline CYP3A7 & 1.35 & 1.30 & $5.54 \pm 9.63$ & 173.80 & $0.10-33.73$ & 13 \\
\hline CYP4F2 & 10.97 & 2.60 & $12.22 \pm 5.74$ & 46.99 & $2.98-22.36$ & 23 \\
\hline CYP4F11 & 4.54 & 1.10 & $5.06 \pm 2.47$ & 48.86 & $1.37-13.69$ & 23 \\
\hline CYP4F12 & 0.58 & 0.45 & $1.23 \pm 1.51$ & 122.27 & $0.06-5.27$ & 18 \\
\hline CYB5A $^{e}$ & 160.05 & 23.40 & $169.19 \pm 49.63$ & 29.33 & $88.69-260.67$ & 23 \\
\hline$P^{\prime} R^{e}$ & 38.86 & 10.10 & $41.17 \pm 14.20$ & 34.49 & $18.53-74.73$ & 23 \\
\hline
\end{tabular}


Table 2 - Expression levels of 10 uridine-5'-diphospho-glucuronosyltransferase (UGT) enzymeswith known involvement in drug glucuronidation in human liver microsomal fractions. Protein expression is represented by the median, the median absolute deviation (MAD), the mean, the standard deviation of the mean (SD), the coefficient of variation (CV) and the range (min - max). Abundance of UGTs is expressed in pmol $\mathrm{mg}^{-1}$ of liver microsomal protein.

\begin{tabular}{ccccccc}
\hline \multirow{2}{*}{ Enzyme } & Median & MAD $^{a}$ & Mean $\pm \mathbf{S D}^{b}$ & $\boldsymbol{C V}$ & Range & $\boldsymbol{n}^{d}$ \\
\cline { 2 - 7 } & $p m o l \mathrm{mg}^{-1}$ & $p m o l \mathrm{mg}^{-1}$ & $p m o l \mathrm{mg}^{-1}$ & $\%$ & $\begin{array}{c}(\mathrm{min}-\mathrm{max}) \\
p m o l \mathrm{mg}^{-1}\end{array}$ & \\
\hline UGT1A1 & 12.29 & 4.60 & $17.13 \pm 12.81$ & 74.79 & $2.08-53.64$ & 23 \\
UGT1A3 & 1.36 & 0.80 & $2.21 \pm 2.55$ & 115.72 & $0.33-11.58$ & 23 \\
UGT1A4 & 22.70 & 8.90 & $26.06 \pm 12.41$ & 47.63 & $11.18-49.88$ & 23 \\
UGT1A6 & 7.89 & 5.50 & $9.64 \pm 7.69$ & 79.81 & $0.90-29.10$ & 23 \\
UGT1A9 & 5.19 & 2.40 & $7.18 \pm 6.47$ & 90.13 & $1.07-25.00$ & 23 \\
UGT2B4 & 24.57 & 10.10 & $24.64 \pm 12.06$ & 48.95 & $8.36-50.58$ & 23 \\
UGT2B7 & 56.17 & 14.90 & $53.97 \pm 22.84$ & 42.31 & $10.86-100.37$ & 23 \\
UGT2B10 & 1.92 & 1.40 & $3.99 \pm 4.29$ & 107.71 & $0.39-13.84$ & 23 \\
UGT2B15 & 15.42 & 5.60 & $16.18 \pm 7.85$ & 48.54 & $4.80-35.12$ & 23 \\
UGT2B17 & 5.43 & 3.45 & $7.81 \pm 7.93$ & 101.47 & $0.38-26.50$ & 16 \\
\hline
\end{tabular}


Table 3 - Expression levels of 18 transporters with known involvement in drug clearance in human liver microsomal fractions. Protein expression is represented by the median, the median absolute deviation (MAD), the mean, the standard deviation of the mean (SD), the coefficient of variation (CV) and the range (min - max). Proteins highlighted in blue have been quantified for the first time in this study. Abundance of transporters is expressed in pmol $\mathrm{mg}^{-1}$ of liver microsomal protein.

\begin{tabular}{|c|c|c|c|c|c|c|}
\hline \multirow{2}{*}{ Transporter } & Median & $M A D^{a}$ & Mean $\pm S D^{b}$ & $C V^{c}$ & Range & $n^{d}$ \\
\hline & pmol mg-1 & $\mathrm{pmol} \mathrm{mg}^{-1}$ & pmol mg-1 & $\%$ & $\begin{array}{c}(\min -\max ) \\
\mathrm{pmol} \mathrm{mg}^{-1}\end{array}$ & \\
\hline \multicolumn{7}{|c|}{ ATP-binding cassette transporters } \\
\hline ABCA8 & 0.27 & 0.10 & $0.28 \pm 0.15$ & 51.96 & $0.08-0.53$ & 13 \\
\hline$A B C B 1$ & 0.18 & 0.09 & $0.47 \pm 0.77$ & 162.43 & $0.04-2.95$ & 16 \\
\hline$A B C B 4$ & 0.36 & 0.25 & $0.50 \pm 0.41$ & 81.92 & $0.09-1.21$ & 8 \\
\hline$A B C B 11$ & 0.22 & 0.13 & $0.28 \pm 0.21$ & 76.26 & $0.03-0.90$ & 21 \\
\hline$A B C C 2$ & 0.54 & 0.25 & $0.73 \pm 0.49$ & 67.93 & $0.22-1.55$ & 12 \\
\hline$A B C C 3$ & 0.25 & 0.10 & $0.74 \pm 1.40$ & 188.35 & $0.11-5.42$ & 18 \\
\hline$A B C C 6$ & 0.70 & 0.30 & $1.02 \pm 1.47$ & 145.01 & $0.15-6.60$ & 21 \\
\hline
\end{tabular}

\section{Solute carrier transporters}

\begin{tabular}{lllllll|}
\hline \hline SLC16A2 & 0.33 & 0.20 & $0.47 \pm 0.35$ & 73.27 & $0.12-1.04$ & 8 \\
\hline SLC22A1 & 1.02 & 0.40 & $1.35 \pm 0.93$ & 69.19 & $0.18-4.09$ & 22 \\
SLC22A7 & 0.43 & 0.25 & $0.79 \pm 0.87$ & 110.53 & $0.15-3.36$ & 14 \\
SLC22A9 & 0.77 & 0.35 & $0.88 \pm 0.48$ & 54.35 & $0.36-1.75$ & 14 \\
\hline SLC22A18 & 1.31 & 0.50 & $1.52 \pm 0.82$ & 54.04 & $0.38-3.15$ & 21 \\
\hline SLC29A1 & 0.18 & 0.10 & $0.18 \pm 0.08$ & 43.49 & $0.08-0.35$ & 13 \\
\hline SLC31A1 & 1.46 & 0.40 & $1.61 \pm 0.69$ & 42.72 & $0.62-3.62$ & 21 \\
\hline SLC29A3 & 0.04 & 0.02 & $0.06 \pm 0.04$ & 66.02 & $0.02-0.14$ & 11 \\
\hline SLCO1B1 & 1.98 & 0.60 & $2.45 \pm 1.59$ & 64.65 & $0.96-8.04$ & 23 \\
SLCO1B3 & 0.47 & 0.20 & $0.77 \pm 0.83$ & 107.93 & $0.12-3.25$ & 14 \\
SLCO2B1 & 0.63 & 0.30 & $0.89 \pm 0.58$ & 65.08 & $0.12-2.36$ & 19 \\
\hline
\end{tabular}

${ }^{a}$ Median absolute deviation - a non-parametric measure of variability around the median

${ }^{b}$ Standard deviation - describes variability around the mean where data is expected to be extraction from a normally-distributed population. SD describes both technical and biological variability

${ }^{c}$ Coefficient of variation calculated as a percentage $\left(C V=S D_{i} / \bar{x}_{i}\right)$ for each enzyme $i$

${ }^{d}$ Number of human liver microsomal samples 

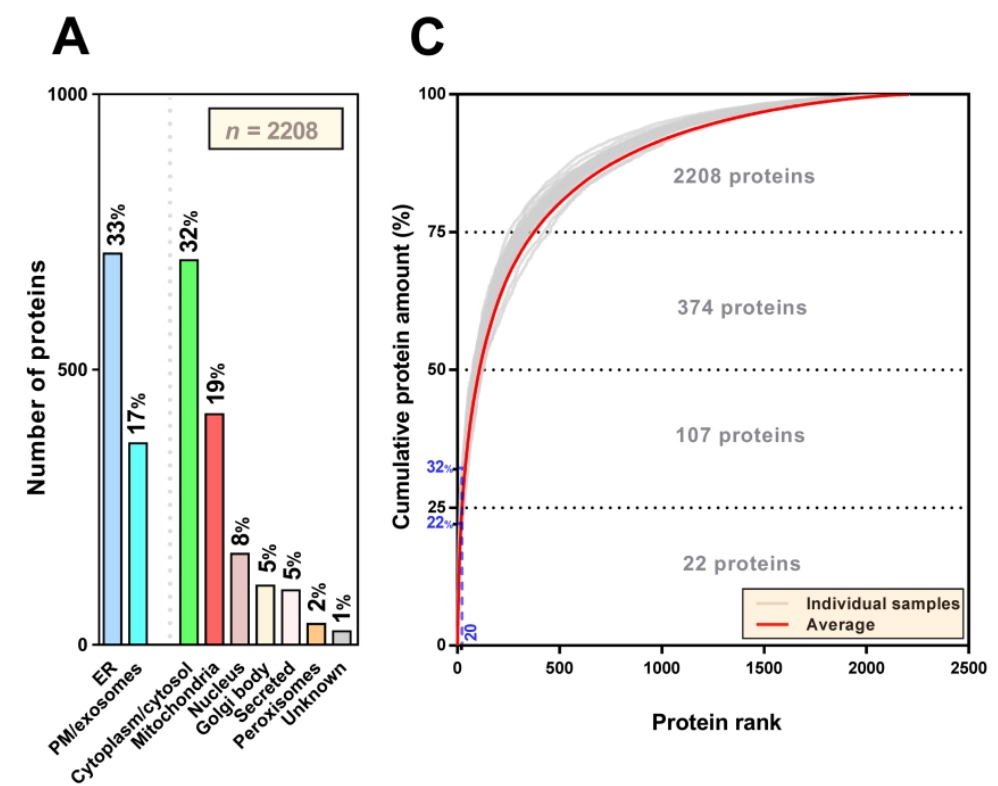

\section{B}

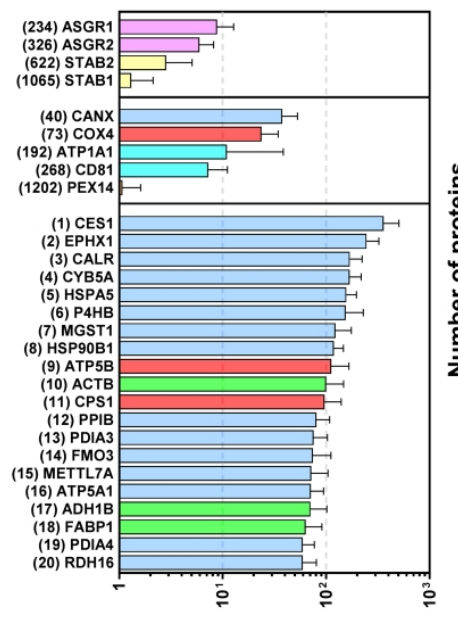

Protein abundance $\left(\mathrm{pmol} \mathrm{mg}^{-1}\right.$ )

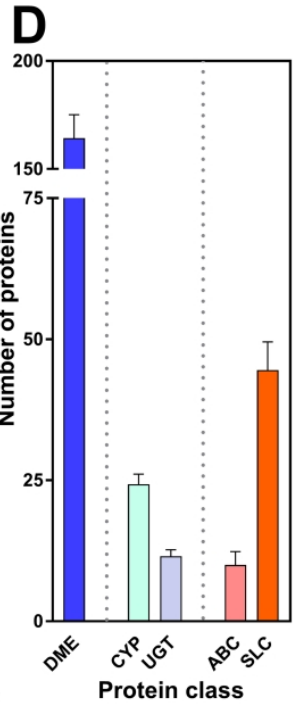

E
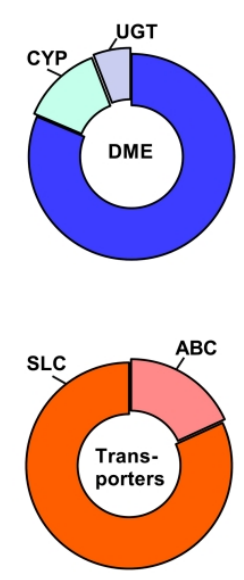

Figure 1 Global proteomic analysis of human liver microsomes ( $n=23$ samples), showing the sub-cellular localization of identified proteins (A), and the origin of the 20 most abundantly expression proteins mapped along with cell and organelle markers (B), showing that this fraction is contaminated due to presence of different cell types (Cell markers; ASGR1/2: hepatocytes, STAB1/2: liver endothelial cells) and cosedimentation of several cellular components (Organelle markers; CANX: endoplasmic reticulum,

ATP1A1/CD81: plasma membrane, COX4: mitochondria, PEX14: peroxisomes); the 20 most abundant proteins were of three origins: reticular, mitochondrial and cytoplasmic/cytosolic. The cumulative amount of the quantified proteins (C), representing assessment of purity of the microsomal fraction, shows contribution of the 20 most highly abundant proteins to total protein amount (22\%-32\%). A large number of drug and xenobiotic metabolizing and transporting proteins were identified in the HLM samples (D), amongst which cytochrome P450 enzymes, UGTs, ABC and SLC transporters (E) are of particular interest. In A, the numbers of proteins in each sub-cellular component is shown along with percentage contribution to the total number of proteins; these percentages add up to more than $100 \%$ due to expression of several proteins in more than one sub-cellular location. ABC, ATP-binding cassette transporters; CYP, cytochrome P450 
enzymes; DME, drug/xenobiotic metabolizing enzymes; ER, endoplasmic reticulum; PM, plasma membrane; SLC, solute carrier transporters; UGT, uridine 5'-diphospho-glucuronosyltransferases.

\section{$142 \times 201 \mathrm{~mm}(600 \times 600 \mathrm{DPI})$}



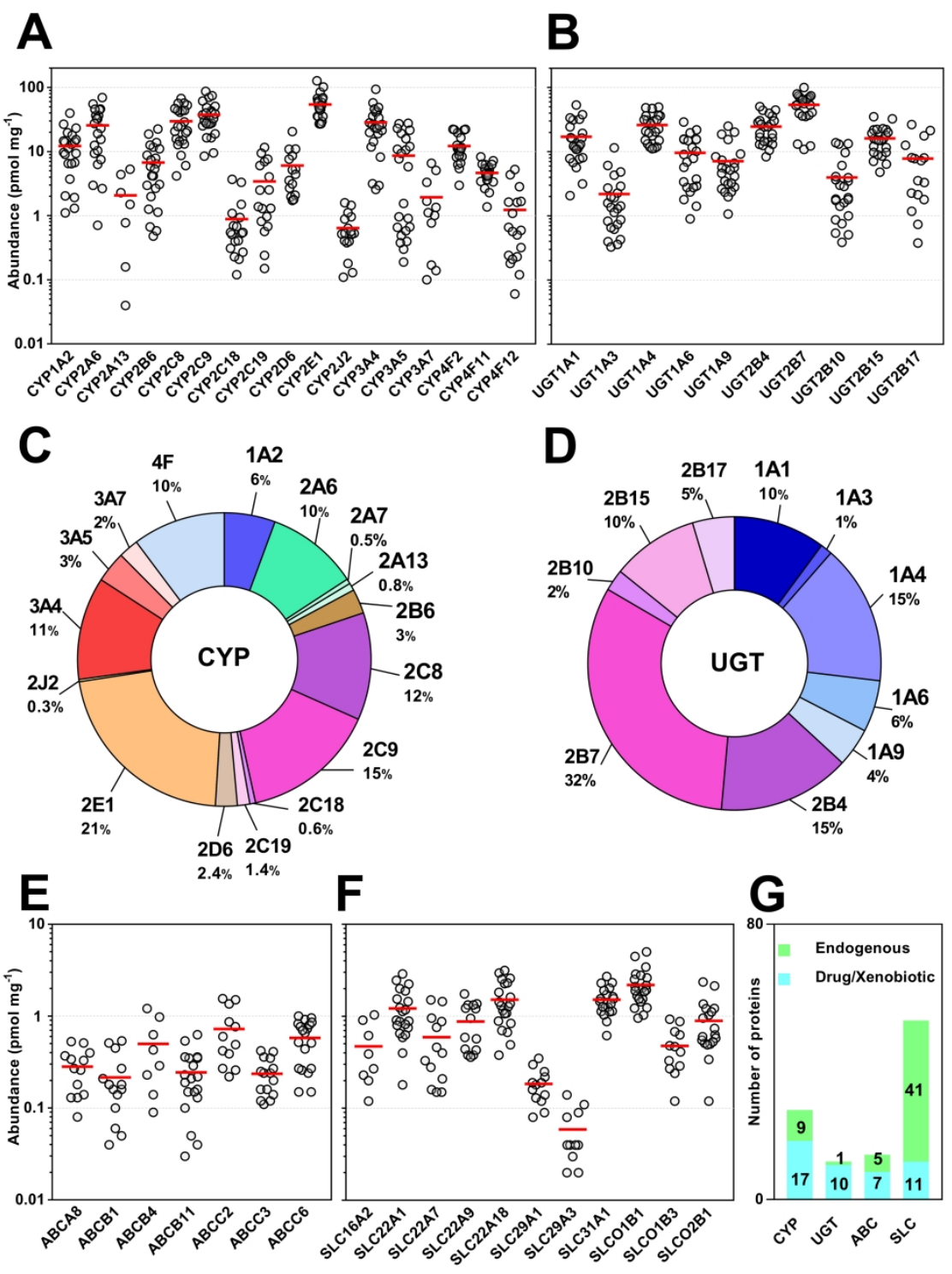

Figure 2 Scatter plots and pie charts representing the abundance of drug-metabolizing cytochrome P450 ( $A$, C) and UGT (B, D) enzymes; scatter plots of the abundance of $A B C(E)$ and SLC (F) drug transporters; and bar chart of the numbers of quantified enzymes and transporters involved in the metabolism and transport of drugs and endogenous compounds (G). In A, B, E and F, the red bars represent mean abundance levels expressed in picomoles per milligram microsomal protein. In G, CYP, cytochrome P450 enzymes; UGT, uridine 5'-diphospho-glucuronosyltransferases; ABC, ATP-binding cassette transporters; SLC, solute carrier transporters; drug and endogenous refer to substrates of enzymes and transporters.

\section{$143 \times 186 \mathrm{~mm}(600 \times 600 \mathrm{DPI})$}




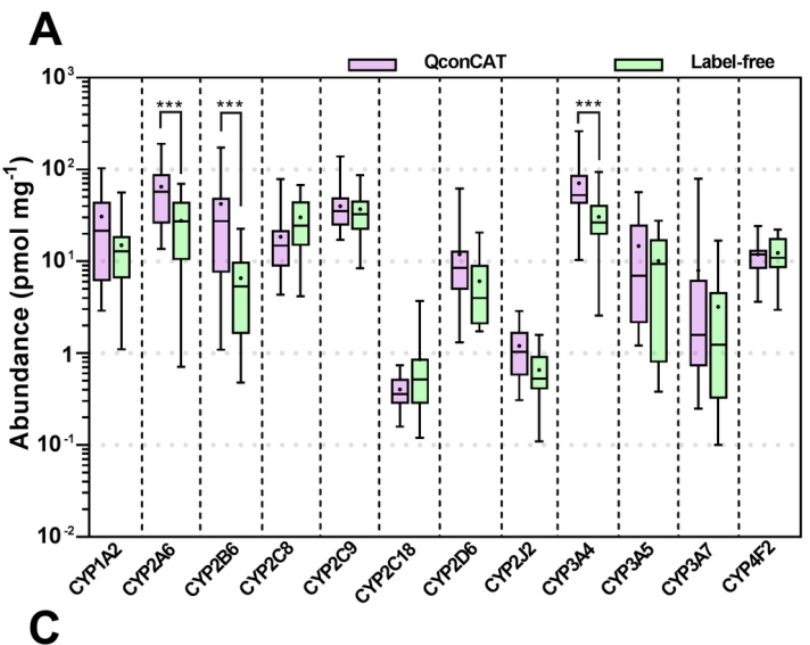

B
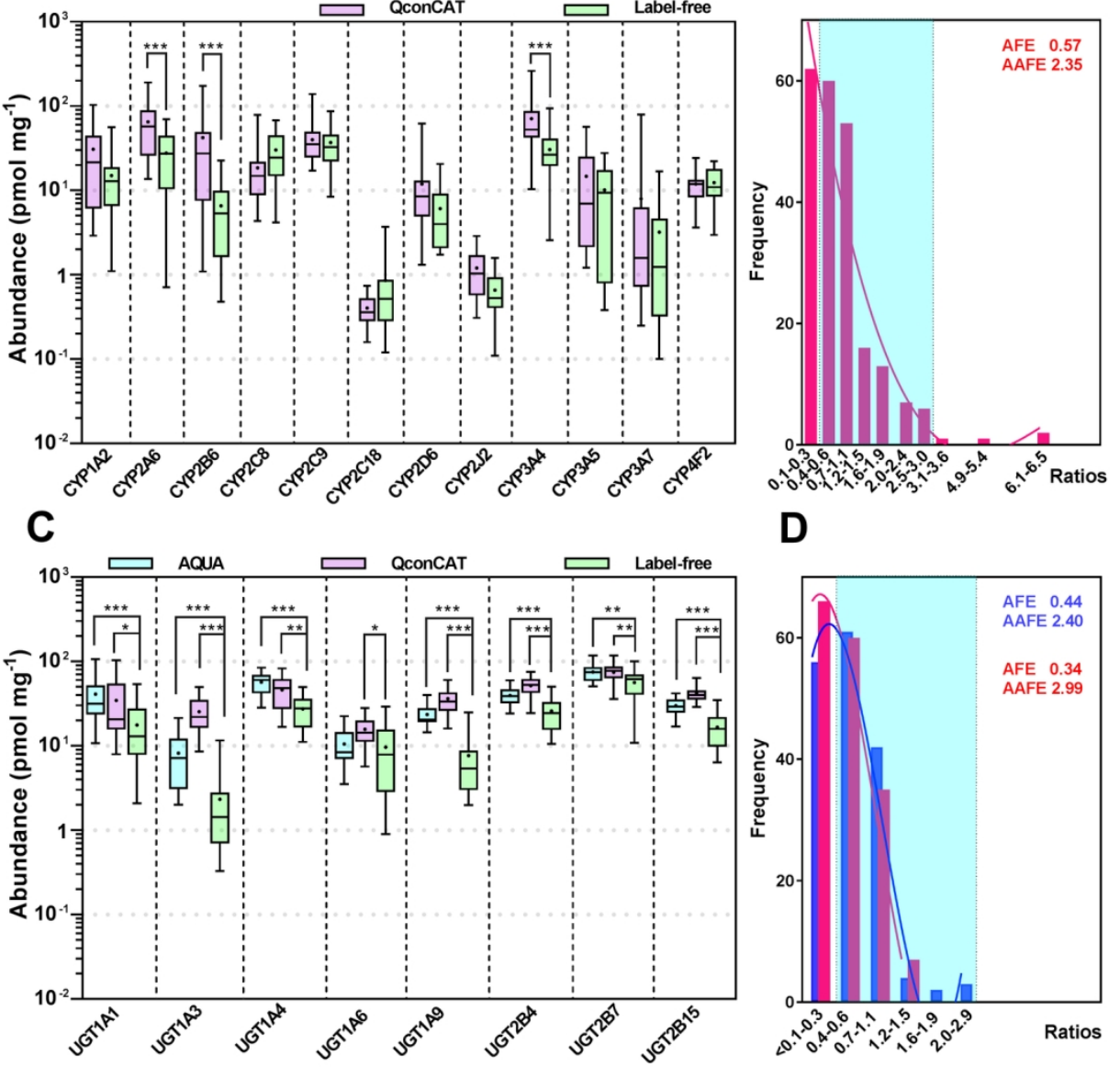

D

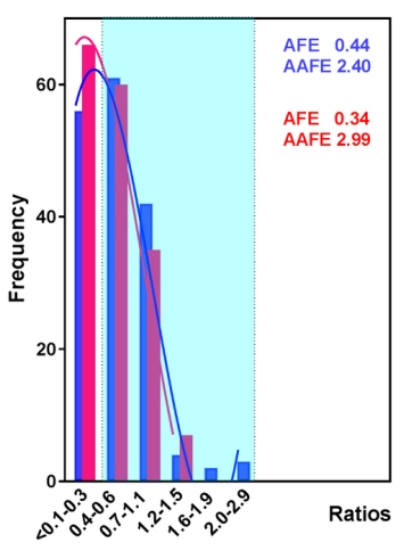

Figure 3 Comparison of abundance values measured using the label-free strategy relative to two targeted methods (AQUA and QconCAT) for cytochrome P450 enzymes (A and B) and UDP-glucuronosyltransferases ( $C$ and $D$ ) in matched liver microsomal samples $(n=21)$. In $A$ and $C$, enzyme abundances are shown as box and whiskers plots with the whiskers representing the ranges, the boxes representing the 25th and 75th centiles, the lines showing the medians and the + signs denoting the means. Mann-Whitney tests were used to assess differences with statistically significant discrepancies shown; *, $\mathrm{P}<0.05 ; * *, \mathrm{P}<0.01 ; * * *$, $P<0.001$. In $B$ and $D$, fold error values are plotted as a frequency distribution showing lower values generated by label-free quantification. Fold errors are calculated as $\llbracket x_{-} 1 / x \rrbracket \_2$ ratios for label free measurements (x_1) relative to targeted measurements (x_2) using either QconCAT (C) or AQUA and QconCAT (D). The light-blue shaded area indicates values within 3-fold, considered as generally interchangeable. AFE, average fold error; AAFE, absolute average fold error; abundance levels are expressed in picomoles per milligram HLM protein.

$139 \times 139 \mathrm{~mm}(300 \times 300 \mathrm{DPI})$ 

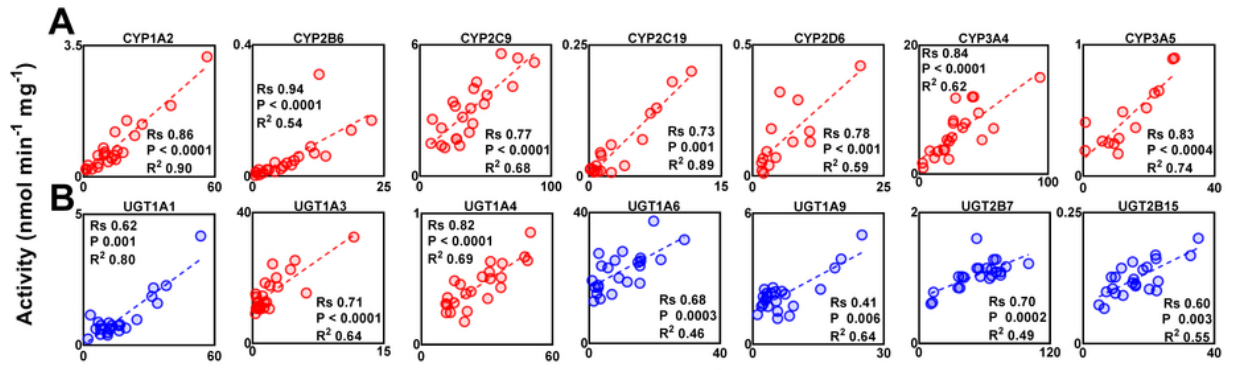

Abundance (pmol mg-1)

Figure 4 Correlation of the abundance levels of cytochrome P450 (A) and uridine 5'-diphosphoglucuronosyltransferase enzymes (B) measured using label-free global proteomics against catalytic activity. Strong and significant correlations (Rs> 0.70, $P<0.008)$ with very limited scatter $(R 2>0.50)$ are shown in red; moderate correlations (Rs>0.50, P < 0.008) with limited scatter $(R 2>0.30)$ are shown in blue. CYP substrates: CYP1A2 (phenacetin), CYP2B6 (bupropion), CYP2C9 (diclofenac), CYP2C19 (S-mephenytoin), CYP2D6 (bufuralol), CYP3A4 (testosterone), CYP3A5 (medazolam). UGT substrates: UGT1A1 ( $\beta$-estradiol),

UGT1A3 (chenodeoxycholic acid), UGT1A4 (trifluoperazine), UGT1A6 (5-hydroxytryptophol), UGT1A9 (propofol), UGT2B7 (zidovudine), UGT2B15 (S-oxazepam). Abundance is measured in units of picomoles enzyme per milligram microsomal protein, and activity is measured in units of nanomoles per minute per milligram microsomal protein. The CYP3A5 activity was measured in the presence of a CYP3cide to silence CYP3A4.

$41 \times 14 \mathrm{~mm}(600 \times 600 \mathrm{DPI})$ 
Figure 5 Covariates of expression of hepatic cytochrome P450 and UGT enzymes measured using the labelfree proteomic strategy. The variables assessed were sex (A, B), age (C), genotype (D) and body mass index, BMI (E). Sex did not affect expression with no significant differences between male and female donors (A and B). An overall declining trend with age was observed for all enzymes, with little statistical significance except for a few UGT examples (C). Genotype was a significant factor for CYP3A5 expression with $* 1 / * 3$ genotype being expressed at higher levels than $* 3 / * 3$ (16-fold higher). Only borderline significant difference in expression was seen between CYP2D6 genotypes (C). There was an overall declining trend of expression with BMI with differences of expression observed between normal weight, overweight and moderately obese patients (D) assessed using ANOVA and Mann-Whitney test for group and pairwise analysis. In A, B and D, abundance data are presented as mean \pm SD. In C, Rs is Spearman rank-order correlation coefficient. In $\mathrm{E}$, the boxes are the 25th and 75th centiles, the whiskers are the ranges, the lines are the medians and the + signs are the means. The scale inset on the right is the BMI scale for the three

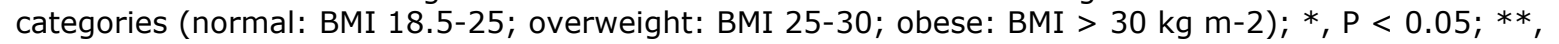
$\mathrm{P}<0.01 ; * * *, \mathrm{P}<0.001$.

$98 \times 64 \mathrm{~mm}(600 \times 600 \mathrm{DPI})$ 
Figure 6 Heat maps showing the abundance levels of drug metabolizing cytochrome P450 (A) and UDPglucuronosyltransferase (B) enzymes in the microsomal samples. Cluster generation was based on rankorder correlation of normal log-transformed expression data. Blue shows low abundances and red high abundances. The red shaded boxes denote the main correlation clusters in the two enzyme families.

Examples of significant correlations within CYP and UGT data are shown in panels (C) and (D), respectively. Strong correlations are shown in red and moderate ones in blue. Correlation statistics are provided in Supporting Information. Abundance levels are expressed in picomoles per milligram HLM protein.

$154 \times 107 \mathrm{~mm}(300 \times 300 \mathrm{DPI})$ 


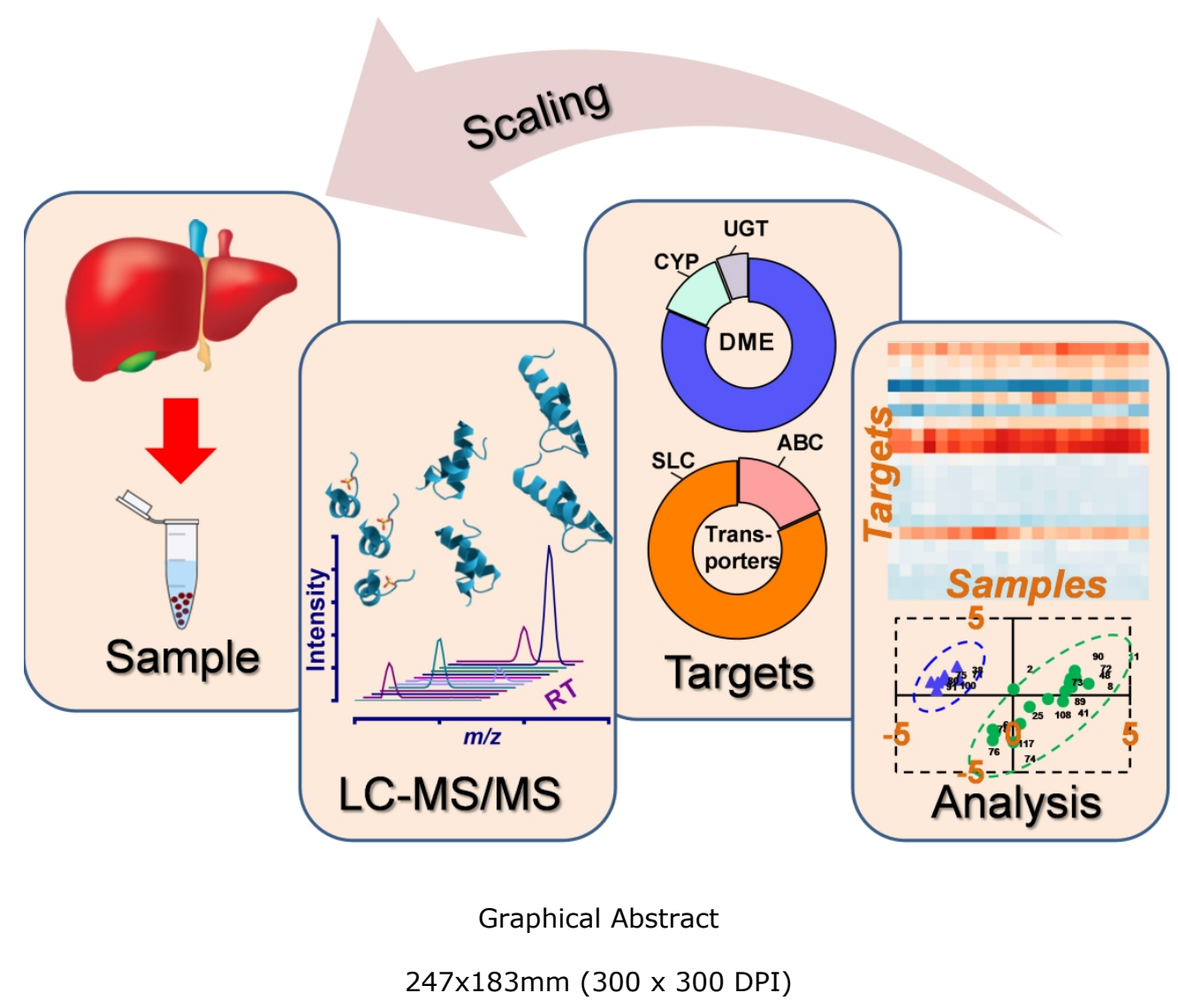

ACS Paragon Plus Environment 